INVESTIGACIONES

de HISTORIA ECONÓMICA

2005, primavera, número 2. Pp. 39 a 74

\title{
El mercado de factores en la agricultura murciana durante el siglo XIX
}

\section{The factor's market in Murcian agriculture in the $19^{\text {th }}$ century}

\author{
MARÍA TERESA PÉREZ PICAZO \\ Universidad de Murcia
}

\begin{abstract}
RESUMEN
El objetivo de este artículo consiste en una reflexión sobre la posible influencia de la dotación de factores de producción sobre el modelo de crecimiento económico de Murcia. El trabajo se ha articulado en tres apartados, a lo largo de los cuales se presentan las características y evolución de la oferta y la demanda de tierra, trabajo y capital durante el XIX. Se ha insistido especialmente en el peso de los condicionamientos ambientales, el incremento de la densidad demográfica, la tendencia a la ruralización y las estructuras agrarias. En lo relativo a estas últimas, se ha destacado el predominio de la gestión indirecta apoyada en la pequeña explotación campesina. Las conclusiones señalan los mecanismos a través de los cuales estos elementos orientaron la interacción factorial y las estrategias de los agentes económicos.
\end{abstract}

\section{ABSTRACT}

The focus of this paper is to shed light about the argument in favour of an influence of a production resources endowment with different intensity on the economic growth model of Murcia. This paper has been structured in three parts, to present the characteristics and evolution of earth, labour and capital supply and demand in the $19^{\text {th }}$ century. Attention has been mainly paid to the importance of environmental factors, a growing demographic density, a rural process tendency and the agrarian structures for the mentioned resources evolution. For the effects of agrarian structures the main analysed factor has been the dominance of indirect management based on small farms. According to the main conclusions, the mentioned factors were acting through particular mechanisms to guide the resources interaction and the economic agents' strategies.

KEY WORDS: Market, Land, Labour, Capital

JEL Codes: Q13 


\section{Introducción ${ }^{1}$}

$\mathrm{E}$ n la última década ha comenzado a incrementarse la publicación de trabajos sobre el funcionamiento de las economías rurales españolas durante los siglos XIX y XX. Sus autores han atendido especialmente a la identificación de aquellos factores cuya presencia pueda explicar las diferentes versiones regionales del crecimiento agrario. Gallego hace referencia al modo de acceso a la tierra y al trabajo, al nivel de mercantilización de la producción y al coeficiente de industrialización ${ }^{2}$; Pujol, González de Molina y Fernández Prieto destacan las restricciones medioambientales y tecnológicas al crecimiento agrícola ${ }^{3}$; y Domínguez y Llopis enfatizan determinadas variables demográficas y económicas (la urbanización, las migraciones y los cambios en la estructura sectorial de la población activa $)^{4}$. Algunos de ellos, además, combinan en sus hipótesis explicativas los factores anteriores con otros de distinta índole; así, González de Molina y Llopis insisten en el peso del contexto institucional —al que el segundo autor añade el de la herencia histórica—; Garrabou, Simpson y Carmona se interesan por las estructuras agrarias ${ }^{5}$; y Simpson incorpora determinadas cuestiones relativas al nivel de vida (dieta alimenticia, acceso a la alfabetización).

Éste es el contexto en el que se inserta el presente artículo, en el cual se plantea una nueva hipótesis que dé cuenta de los caracteres específicos del cambio agrario en Murcia durante el siglo XIX. Hipótesis sustentada en la idea de convertir la dotación relativa de factores de producción en el punto de mira desde el cual se enfoque el análisis del proceso en cuestión, dada la influencia que debió de ejercer en las opciones de los agentes económicos. Parece lógico, en efecto, que la intensidad - en el sentido que confiere a este término Maxine Berg (1987) — en el uso de la tierra, el trabajo y el capital estuviera condicionada por su abundancia relativa a lo largo del período considerado. La idea no es nueva: en gran número de estudios sobre los modelos de Revolución Industrial se ha introducido como eje expositivo, tanto más cuanto que facilita el establecimiento de comparaciones.

Un mejor conocimiento del crecimiento murciano puede aportar nuevos elementos al controvertido debate sobre el "atraso" agrario debido a la prolongada pre-

1 Quiero agradecer las críticas y comentarios de los colegas que asistieron a la presentación de este trabajo en el marco del VI Seminario Complutense de Historia Económica, especialmente a Enrique Llopis y Carmen Sarasúa. Asimismo, a mis compañeros de departamento que hicieron otro tanto cuando se discutió un primer borrador del mismo y, por último, a los tres evaluadores anónimos. Los errores son responsabilidad exclusiva de la autora.

Gallego (1998), (2001a) y (2001b).

Pujol (2001), González de Molina (2001), Fernández Prieto (2001).

Domínguez y Guijarro (2000), Domínguez (2002), Llopis (2002).

Garrabou (2001), Carmona y Simpson (1999) y (2003).

Simpson (1995) y (2002). 
sencia de contradicciones en su seno ${ }^{7}$. En especial, el hecho de que la construcción de una agricultura intensiva, dinámica y especializada, generadora de externalidades positivas en los sectores secundario y terciario, no bastara para acelerar el ritmo del proceso. En efecto, si se establecen comparaciones con otras regiones españolas se comprueba que, desde 1860 por lo menos, Murcia quedó integrada en el grupo de las de "lenta velocidad" (Andalucía, Extremadura, Castilla-La Mancha, Castilla y León, Galicia). El Índice Físico de Calidad de Vida calculado por Domínguez ${ }^{8}$ (mortalidad infantil, esperanza de vida, alfabetización) ya estaba por debajo de la media nacional en dicha fecha, y otro tanto sucedía con los demás indicadores socioeconómicos señalados por dicho autor. En cuanto a la renta per capita, se estanca entre el 70 y el 80 por 100 de la española desde 1800 hasta el año 2000.

La articulación del trabajo se apoya, obviamente, en la presentación de los rasgos fundamentales asumidos por la oferta y la demanda de los factores de producción a lo largo del período considerado, razón de ser de los tres apartados en que se divide. El telón de fondo de la evolución está constituido, desde el punto de vista ambiental, por un medio físico difícil — la España árida—; desde el geopolítico, por una ordenación del territorio apoyada en el gran municipio; $y$, desde el social, por unas estructuras agrarias dominadas por la concentración de la propiedad y el predominio de la gestión indirecta. Mi propuesta epistemológica, que matiza las posiciones neoinstitucionalistas, defiende que el nivel de desarrollo económico alcanzado no fue consecuencia exclusiva del mejor o peor funcionamiento de la circulación mercantil, tanto de factores como de productos, sino de su interacción con las variables indicadas.

Para terminar, unas palabras sobre las características de la coyuntura durante las décadas bisagra entre los siglos XVIII y XIX, punto de partida temporal de este artículo. Al igual que en el conjunto del país, la economía murciana atraviesa una larga crisis de la que no saldrá hasta los años 1835-1840 . Aparte de los problemas ligados a los cambios político-institucionales, de todos conocidos, es necesario tener en cuenta los problemas que atravesaba el modelo económico heredado del Antiguo Régimen, caracterizado por la extraversión y por la existencia de un equilibrio inestable entre los cultivos de subsistencia y los orientados a la comercialización. Tal equilibrio se vio alterado a partir de dichas décadas por el aumento de la densidad de población, que incrementó la demanda de cereales, y por la pérdida de mercados exteriores para la lana y la barrilla, con la consiguiente dificultad para saldar las importaciones de los primeros. Aparece así, con toda claridad, la fisonomía a la vez frágil y dinámica del modelo indicado, en un período durante el cual los mercados de tierra y capital no funciona-

Pérez Picazo (2000), Pérez Picazo y Martínez Carrión (2001), Martínez Carrión (1987) y (2002a).

Domínguez (2002), p. 257 y ss.

Ver análisis comparativo a escala nacional en Pérez Picazo (1998), pp. 427 y ss., y Llopis (2001). 
ban de forma eficiente debido al marco institucional. La reforma agraria liberal iba a constituir, como he mostrado en otras publicaciones, un giro decisivo al respecto ${ }^{10}$.

\section{El mercado de la tierra}

En lo que respecta a la oferta, la principal característica de la de origen público, es decir, la procedente de la Desamortización, consistía en la moderada porción de suelo incluida en los bienes de manos muertas, un 12,4 por 100 de la superficie cultivada, mientras que los propios y comunes ocupaban un porcentaje considerablemente mayor (el 31,4 por 100). En cuanto a la oferta privada, su rasgo definitorio era la importancia de la propiedad vinculada, que ocupaba en torno a un 50-60 por 100 de los regadíos y un 40-70 por 100 de los secanos (Pérez Picazo, 1990a, p. 91); fenómeno este último que había reducido las dimensiones del mercado de bienes raíces a fines del Antiguo Régimen, dificultando el acceso a los mismos por vías distintas a las de la herencia. Se trata de un problema característico de la corona de Castilla; las escasas monografías en las que se ha intentado medir su alcance confirman la importancia absoluta y relativa de las porciones de suelo incluidas en mayorazgos ${ }^{11}$.

Esta oferta limitada de tierras coincidía con un fuerte aumento de la demanda desde la segunda mitad del XVIII. Aumento atribuible, por un lado, a la modesta acumulación lograda en una coyuntura alcista por las clases medias rurales y urbanas; y, por otro, al "hambre de tierra" de los campesinos, cuyo dinamismo demográfico había hecho progresar la ocupación de unos campos semivacíos hasta el siglo XVIII ${ }^{12}$. Ambos fenómenos estuvieron presentes en la mitad meridional del territorio peninsular, donde la subocupación del espacio era la norma ${ }^{13}$. De ahí que las reformas liberales generaran una brusca subida de las operaciones de compraventa, especialmente importante en lo relativo a las fincas procedentes de la Desamortización de Madoz y de la Desvinculación. Entre 1859 y 1926, se privatizó en Murcia un 65 por 100 del patrimonio comunal, porcentaje muy superior al alcanzado por la media española, cifrada en un 41 por $100^{14}$. En cuanto a las ventas de tierras vinculadas, la muestra presentada en el Cuadro 1 permite apreciar que supusieron cerca de la mitad del total (el 41,9 por 100).

Sobre el mercado de la tierra, Pérez Picazo (1990a); sobre el de trabajo, Pérez Picazo (1990b); y sobre el de capital, Pérez Picazo (1987a) y (1987b) y, sobre todo, Martínez Soto (1994), (1998), (2000) y (2001).

11 Toledo, Donézar (1984); Sevilla, Parias (1989); Granada, Ferrer (1982); País Vasco, Herrero (1993).

12 Entre 1787 y 1857, la tasa de crecimiento anual de la población fue del 0,6 por 100, superior a la media nacional. La densidad pasó de 17,2 habitantes $/ \mathrm{km}^{2}$ en 1756, a 22,3 en 1787, y a 33,7 en 1857 . Datos procedentes del Catastro de Ensenada y del Censo de Población de Murcia de 1857.

13 Pérez Picazo (1998), p. 469. Sánchez Salazar lo ha detectado igualmente utilizando como indicador los avances de las roturaciones, tanto autorizadas como clandestinas. Sánchez Salazar (1988).

14 GEHR (1991), pp. 63-68, y (1994), p. 142. 
CUADRO 1

NÚMERO DE OPERACIONES DE VENTA, VENDEDORES Y COMPRADORES Y SUPERFICIE VENDIDA SEGÚN SU PROCEDENCIA, 1836-1862

\begin{tabular}{|c|c|c|c|c|c|c|c|}
\hline & \multicolumn{3}{|c|}{ Número } & \multicolumn{4}{|c|}{ Superficie vendida (has) } \\
\hline & Operaciones & Vendedores & Compradores & Desamortización & Desvinculación & Libre & Total \\
\hline Caravaca & 4.944 & 2.991 & 2.668 & 768 & 9.860 & 6.058 & 16.686 \\
\hline Lorca & 8.588 & 5.175 & 3.974 & 2.663 & 19.825 & 38.035 & 60.523 \\
\hline Murcia & 10.530 & 8.633 & 8.073 & 6.967 & 24.024 & 19.748 & 50.739 \\
\hline Total & 24.062 & 16.799 & 14.715 & 10.398 & 53.709 & 63.841 & 127.948 \\
\hline
\end{tabular}

Fuente: Pérez Picazo y Pérez de Perceval (2004), p.61

La evolución y características de la demanda se han reconstruido utilizando como fuente los Libros de la Contaduría de Hipotecas. He elegido el período 1836-1862, porque a lo largo del mismo se pusieron en vigor las nuevas disposiciones $\mathrm{y}$, como universo de análisis espacial, los partidos de Caravaca, Lorca y Murcia, cuya extensión global es de $5.964 \mathrm{Km}^{2}$ (el 52,7 por 100 de la actual región de Murcia) y cuya población ascendía, según el Censo de 1857, a 213.539 habitantes (el 55,8 por 100 del total en el año mencionado $)^{15}$. El vaciado ulterior de los protocolos correspondientes al partido de Murcia me ha permitido seguir la tendencia hasta 1890.

Tanto en términos absolutos (Cuadro 2), como relativos (Cuadro 3), el partido de Murcia va en cabeza en lo concerniente al número de operaciones practicadas y a los capitales invertidos, pero no respecto a la superficie enajenada, más elevada en Lorca. La puesta en relación de las magnitudes citadas con el número de vecinos y la SAU (Superficie Agraria Útil) ${ }^{16}$ de cada partido (Cuadro 3), confirma que los vecinos de Murcia hicieron menos operaciones per capita pero más por unidad de superficie, y

15 Pérez Picazo y Pérez de Perceval (2004). La opción por los tres partidos judiciales que aparecen en el Cuadro 1 se relaciona, por un lado, con el hecho de que sólo en ellos se conserva íntegramente la fuente utilizada y, por otro, con la presencia en los mismos de los tres sistemas agrarios dominantes en la región: el secano, el regadío y la media montaña.

16 En el caso de Murcia, la SAU coincide con la superficie cultivada, dada la ausencia de pastos permanentes, naturales o artificiales. Para Murcia, Padrón de Riqueza de 1830 (Archivo Municipal, legajo 3.164) y Padrón de Tahúllas de 1860 (Junta de Hacendados, sin signatura); para Lorca, estadísticas municipales de 1841 y 1863 , legajos, 258 y 185; para Caravaca, Padrón de riqueza de 1840 (Archivo Municipal de Calasparra, Cuentas del Conde del Valle de San Juan, Fondos de Caravaca, Caja III). 


\section{CUADRO 2}

NÚMERO DE OPERACIONES Y DISTRIBUCIÓN DE LAS VENTAS (en has y pesetas) EN MURCIA, LORCA Y CARAVACA, 1836-1862.

\begin{tabular}{lcrrrrr}
\hline Partidos & $\begin{array}{c}\text { Superficies } \\
\text { (has) }\end{array}$ & \% del total & \multicolumn{1}{c}{$\begin{array}{c}\text { Ventas } \\
\text { (ptas) }\end{array}$} & \% del total & $\begin{array}{l}\text { Número de } \\
\text { operaciones }\end{array}$ & \% del total \\
\hline Caravaca & 16.886 & 13,2 & 356.318 & 8,06 & 4.944 & 20,5 \\
Lorca & 60.523 & 47,3 & 12.198 .535 & 27,70 & 8.633 & 35,9 \\
Murcia & 50.739 & 39,7 & 28.271 .795 & 64,24 & 10.530 & 43,8 \\
Totales & 127.948 & 100,0 & 40.826 .648 & 100,00 & 24.062 & 100,0 \\
\hline
\end{tabular}

Fuentes: Libros de la Contaduría de Hipotecas. Archivo Histórico Provincial de Murcia, Archivo Histórico Municipal de Lorca y Archivo Municipal de Caravaca. Ver Apéndice.

\section{CUADRO 3}

RELACIÓN DE LAS MAGNITUDES DEL CUADRO 2 CON EL NÚMERO DE VECINOS Y LAS SUPERFICIES AGRARIAS ÚTILES DE MURCIA, LORCA Y CARAVACA, 1836-1863 (media del período)

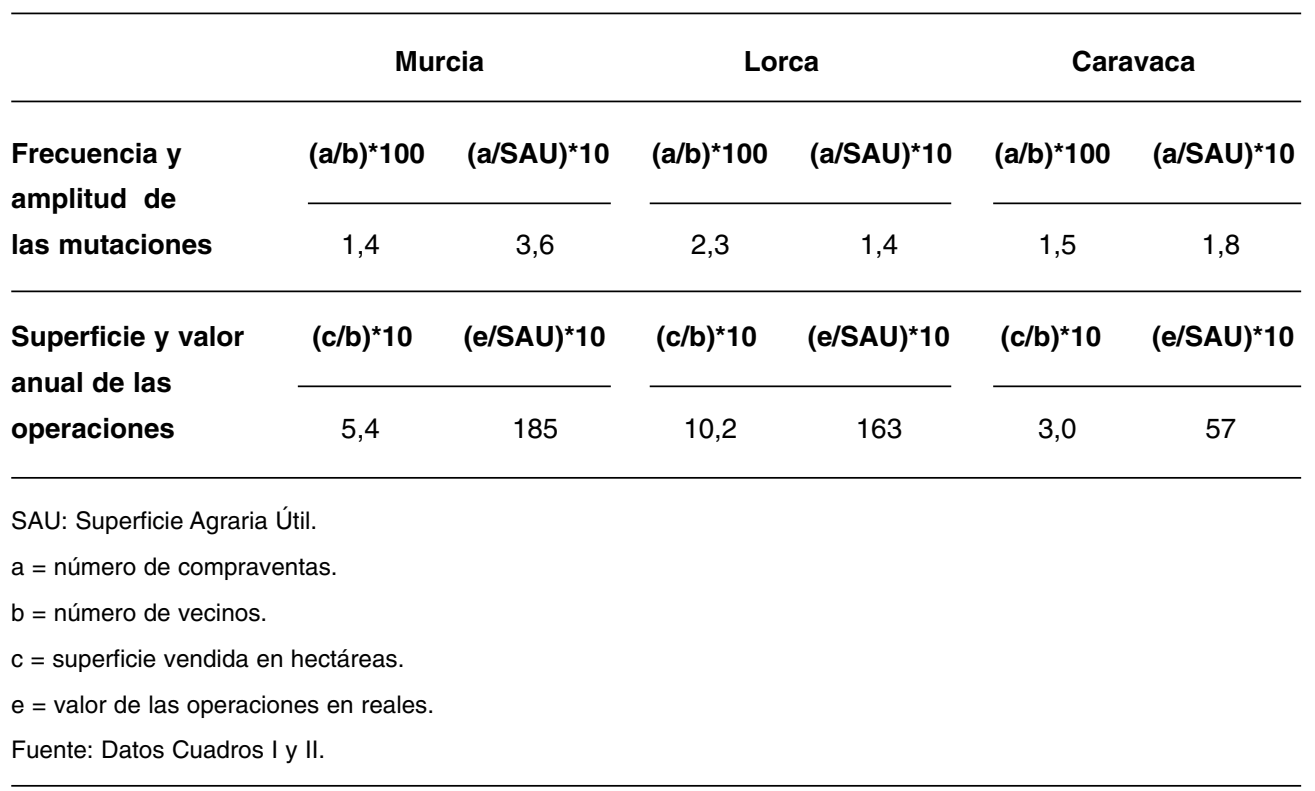


CUADRO 4

SUPERFICIE VENDIDA Y CAPITALES INVERTIDOS EN MURCIA, 1862-1890

$(1836-1862=100)$

\begin{tabular}{lcccccc}
\hline Años & Hectáreas & Índice & Pesetas & Índice & No Operaciones & Índice \\
\hline $\mathbf{1 8 3 6 - 1 8 6 2}$ & 50.739 & 100,0 & 28.271 .795 & 100,0 & 10.530 & 100,0 \\
$\mathbf{1 8 6 2 - 1 8 9 0}$ & 76.108 & 150,0 & 43.388 .751 & 153,5 & 27.827 & 264,6 \\
\hline
\end{tabular}

Fuentes: Libros Contadurías de Hipotecas ya señalados y Protocolos Notariales de Murcia desde 1862 a 1890 (ver Apéndice). Archivo Histórico Provincial de Murcia.

que su nivel de inversión fue mayor que en los otros $\operatorname{dos}^{17}$. Ello es coherente con el reparto de la riqueza a escala regional; el partido capitalino disponía de una economía más diversificada y de unos cultivos más remunerativos, debido a la superioridad de las dotaciones hídricas del valle medio del Segura. En Lorca, por el contrario, lo que cuenta es la considerable dimensión de su circunscripción $\left(2.381 \mathrm{~km}^{2}\right)$ y el menor número de vecinos, que eleva las cifras correspondientes a las operaciones y a la superficie enajenada por habitante, aunque, en realidad, la intensidad de la circulación de la tierra fuese inferior a la registrada en Murcia. Tendencia que se mantuvo, por otra parte, hasta finales del siglo XIX (Cuadro 4). En cuanto a Caravaca, montañosa y mal comunicada, queda por debajo de las otras dos.

Un segundo aspecto a considerar es el balance social de las transacciones. Sabemos que el colectivo vendedor más importante — prescindiendo del Estado- estuvo constituido por los descendientes de la antigua oligarquía terrateniente, titulares de mayorazgos en su mayor parte. En cuanto a los adquirentes, los grupos más favorecidos fueron aquellos que ocupaban lugares intermedios en la escala social; es decir, la burguesía urbana y las clases medias rurales. Ambos se beneficiaron en las operaciones de compraventa de unos costes de información y negociación relativamente más bajos, debido al conocimiento, por un lado, de la situación financiera de gran parte de la población, como era el caso de los comerciantes (muchos de los cuales eran además prestamistas); y, por otro, de la calidad de las fincas enajenadas, como ocurrió con los propietarios/labradores establecidos in situ. El cálculo de la tasa de cobertura neta de las compras por las ventas confirma que las dos categorías 
extremas (grandes terratenientes y campesinos modestos) se quedaron por debajo de 100 , pese a la fuerte participación de los segundos en las operaciones ${ }^{18}$, mientras que el sector burgués ganó un 661 por 100 en Murcia, un 231 por 100 en Lorca y un 169 por 100 en Caravaca, y el de procedencia rural, un 281, un 203 y un 251 por 100, respectivamente ${ }^{19}$.

Una evolución de estas características difícilmente podía facilitar la redistribución de la propiedad de la tierra. Entre 1850 y 1870, el nivel de concentración de la misma seguía siendo alto (los índices de Gini oscilaban entre 0,77 y 0,86 en el secano, y entre 0,51 y 0,78 en el regadío) y el reparto del suelo entre las categorías extremas de propietarios desequilibrado ${ }^{20}$. Lo cual no impidió que tuviera lugar una doble serie de transformaciones con gran longitud de onda:

1) Puesta en marcha de un proceso de diversificación social. Primero, porque cambia la composición de la élite propietaria al igual que en otros puntos de la geografía española, como Orihuela (Millán, 1999) o Andalucía oriental (Martínez Martín, 1995). Después, porque comienza a producirse un rápido proceso de selección interna en las categorías media y baja de propietarios, del que salió un sector nada desdeñable de cultivadores directos que tendrían un alto grado de protagonismo en el incipiente proceso de cambio agrario.

2) Incremento absoluto y relativo de las unidades de cultivo propias o arrendadas, de carácter familiar y dimensiones reducidas. En líneas generales, la propiedad campesina avanzó modestamente en el secano y perdió posiciones en el regadío, pero los titulares de las parcelas raramente fueron expulsados de las mismas, sino que se convirtieron en arrendatarios.

Tomamos así contacto con un fenómeno de gran alcance en la evolución del mercado de la tierra, igualmente visible en otras regiones mediterráneas como Cataluña, Valencia y Andalucía Oriental ${ }^{21}$. La oferta y la demanda de suelo arrendable se convierten en un elemento a tener en cuenta, especialmente en las comarcas de regadío, donde el crecimiento demográfico había sido mayor y la intensificación de los cultivos avanzaba a buen paso. En la huerta de la capital, por ejemplo, si utilizamos la SAU como dividendo, la densidad pasa de 274 habitantes por $\mathrm{km}^{2}$ en 1857 a 371 en 1900. Intensificación e incremento de la densidad que inspi-

18 El afán de compra de este grupo social constituye un fenómeno conocido. Para los componentes del mismo la ampliación de sus reducidas explotaciones era una necesidad vital, tanto para asegurar la reproducción de las mismas, como para compensar la tendencia a la fragmentación inherente a los sistemas de herencia igualitarios. Sabio Alcutén (1992).

19 Pérez Picazo y Pérez de Perceval (2004), pp. 74-79.

20 Datos procedentes de los Amillaramientos verificados a lo largo de ambas décadas en la práctica totalidad de los municipios de la región. Pérez Picazo (1994).

21 Para Valencia, Calatayud, Millán y Romeo (2002); para Cataluña, Saguer (1998a) y (1998b) y Garrabou, Planas y Saguer (2001); y para Andalucía Oriental, Martínez Martín (1995). 
raron a los propietarios una estrategia dirigida a la fragmentación de las explotaciones, con el consiguiente aumento de sus rentas ${ }^{22}$. El tamaño medio de las unidades de cultivo "modestas" descendió de 1,6 hectáreas en 1822, a 0,98 en 1870 y a 0,59 en $1922^{23}$.

Esta tendencia aparece también, con menos fuerza, en los sistemas de secano, pero apoyada en la aparcería. En su origen se encuentran dos prácticas de signo opuesto, una extensiva - avance de las roturaciones ligada a la expansión de la cerealicultura-, y la otra intensiva — plantaciones de olivos, almendros o algarrobos (campo de Cartagena) y de viñas (altiplano de Yecla-Jumilla)—. Aunque en este último caso el tipo de contrato agrario utilizado fuera la enfiteusis — similar a la rabassa morta $^{24}$ catalana-, sigue en pie el hecho de que la introducción de los nuevos aprovechamientos se estaba verificando mayoritariamente en el marco de explotaciones de carácter familiar. Evolución bastante similar a la que estaba teniendo lugar en aquellas regiones mediterráneas cuyas agriculturas se estaban especializando en determinados productos, como el Peloponeso y Tesalia con la pasa y el tabaco, el Languedoc y el Rosellón con el viñedo y el Sur de Italia con los agrios ${ }^{25}$.

Lo dicho hasta ahora añade argumentos al debate ya viejo sobre la resistencia de la teoría económica convencional a reconocer la eficiencia de la gestión indirecta en el crecimiento agrario cuando asume la forma de explotaciones familiares de tamaño modesto. Carmona y Simpson (2003) han vuelto a formular recientemente el problema, y Garrabou, Planas y Saguer lo resumen en el título de su último libro ¿Un capitalisme imposible? ${ }^{26}$. La inteligente reflexión de Köning (1994) apunta en la misma línea, cuando escribe que la mayor parte de las explotaciones campesinas encontraron una oportunidad de subsistencia, y aun de consolidación, en la especialización productiva.

Tal vez la consecuencia más importante de este proceso de "campesinización"27 consista en que dio lugar a unas estructuras agrarias dominadas por la renta, en gran parte debido a la dotación relativa de factores: abundaba la fuerza de trabajo, pero no la tierra fértil, y el dinero barato, en un período en el que la legislación favorecía desca-

En las tierras que el conde del Valle de San Juan poseía en la huerta murciana, el número de arrendatarios se duplica aproximadamente entre 1836 y 1902: pasa de 176 a 369. Archivo Municipal de Calasparra, Cuentas del conde del Valle de San Juan, Fondos de Murcia, Cajas XXIII y XXIV.

Pérez Picazo, Martínez Carrión y Pérez de Perceval (1998), pp. 121-122.

Carmona y Simpson (1999) y (2003).

Ver un análisis de conjunto sobre la integración de la agricultura mediterránea en el mercado en Pérez Picazo (1995) y Morilla Critz, Olmstead y Rhode (1999). Para Grecia, Dertilis (1992) y (1993), Karouzou (1993) y Petmezas (1997); para el Sur de Italia, Lupo (1990); y para el viñedo mediterráneo francés, los trabajos clásicos de Gavignaud (1983) y Pech (1975).

Colomé (2002), Garrabou, Planas y Saguer (2001).

González de Molina y Sevilla (1991), González de Molina (2001). 
radamente al propietario ${ }^{28}$. De lo que no cabe duda es de la eficiencia del sistema en la consolidación del capitalismo agrario, por lo menos en los casos concretos de Cataluña, Murcia y Valencia, porque los cultivadores se vieron obligados a buscar nuevas fuentes de liquidez para pagar la renta. Unas veces destinaron a ese fin una mayor parte del excedente de la explotación, y otras desarrollaron aprovechamientos de comercialización fácil, ya fueran tradicionales como la seda y el cáñamo ${ }^{29}$, o novedosos como el pimiento para pimentón (Martínez Carrión, 1999). Respuestas todas ellas que favorecieron el establecimiento de vínculos entre el mercado de factores y el de productos.

Resta por aludir, siquiera someramente, a la evolución de la renta de la tierra. Los datos que poseo al respecto cubren prácticamente toda la centuria y proceden de contabilidades privadas pertenecientes a una serie de fincas repartidas en tres de los sistemas agrarios de la región ${ }^{30}$ : el secano, la huerta y el arrozal (Gráfico 1). He elegido como deflactores los precios del arroz (Calasparra) y del trigo (Murcia y Caravaca). El primero, debido a su carácter de monocultivo en el precitado perímetro de regadío; el segundo, porque su cultivo seguía siendo mayoritario a finales del siglo XIX tanto en los espacios de secano como en el interior de las rotaciones complejas practicadas en las huertas.

La comparación entre las diversas trayectorias autoriza las siguientes constataciones:

1) La tendencia secular es ascendente al igual que en Castilla, Navarra y Catalu$\tilde{n} a^{31}$ o en el conjunto del país. Carmona y Simpson han demostrado que el nivel de crecimiento de la renta de la tierra en España superó al alcanzado en numerosos países europeos ${ }^{32}$.

2) La sucesión de tres etapas separadas por fronteras cronológicas imprecisas:

a) 1800-1820. Los niveles de renta, altos a comienzos de siglo, caen bruscamente a partir 1804-1809 y no se recuperan hasta 1820. Ello se produce a consecuencia de la simultaneidad de tres episodios de crisis: bélica, demográfica (malas cosechas y epidemia de fiebre amarilla) y económica (pérdida de mercados exteriores para los productos citados).

28 Ello se detecta en la introducción de cláusulas abusivas en los contratos, como la denominada "a fruto sano", consistente en hacer recaer sobre el explotador los azares de la coyuntura.

29 Las moreras se mantuvieron en los márgenes de las parcelas y de los caminos hasta los años 1940-1950. Algo parecido ocurrió en Orihuela (Calatayud, Millán y Romeo, 2000) y en Castellón con el cultivo del cáñamo (Garrido, 2004, pp. 68-82).

Se trata del patrimonio de conde del Valle de San Juan, dueño de grandes fincas de secano en Murcia (2.271 has.) y Caravaca (4.967 has.), de la mayor parte de los arrozales de Calasparra (257 has.) y de 673 has. en la huerta de Murcia.

31 Para Castilla, Robledo (1984) y Carmona (2001); para Navarra, Lana Berasain (1997); para Cataluña, Garrabou, Planas y Saguer (2001); para Aragón, Sabio (1998).

32 Carmona y Simpson (2003), p. 38. 


\section{GRÁFICO 1}

EVOLUCIÓN DE LA RENTA NETA DE LA TIERRA EN EL REGADÍO (CALASPARRA Y MURCIA) Y EN EL SECANO (CARAVACA), 1800-1900 (medias quinquenales y precios constantes de 1800)

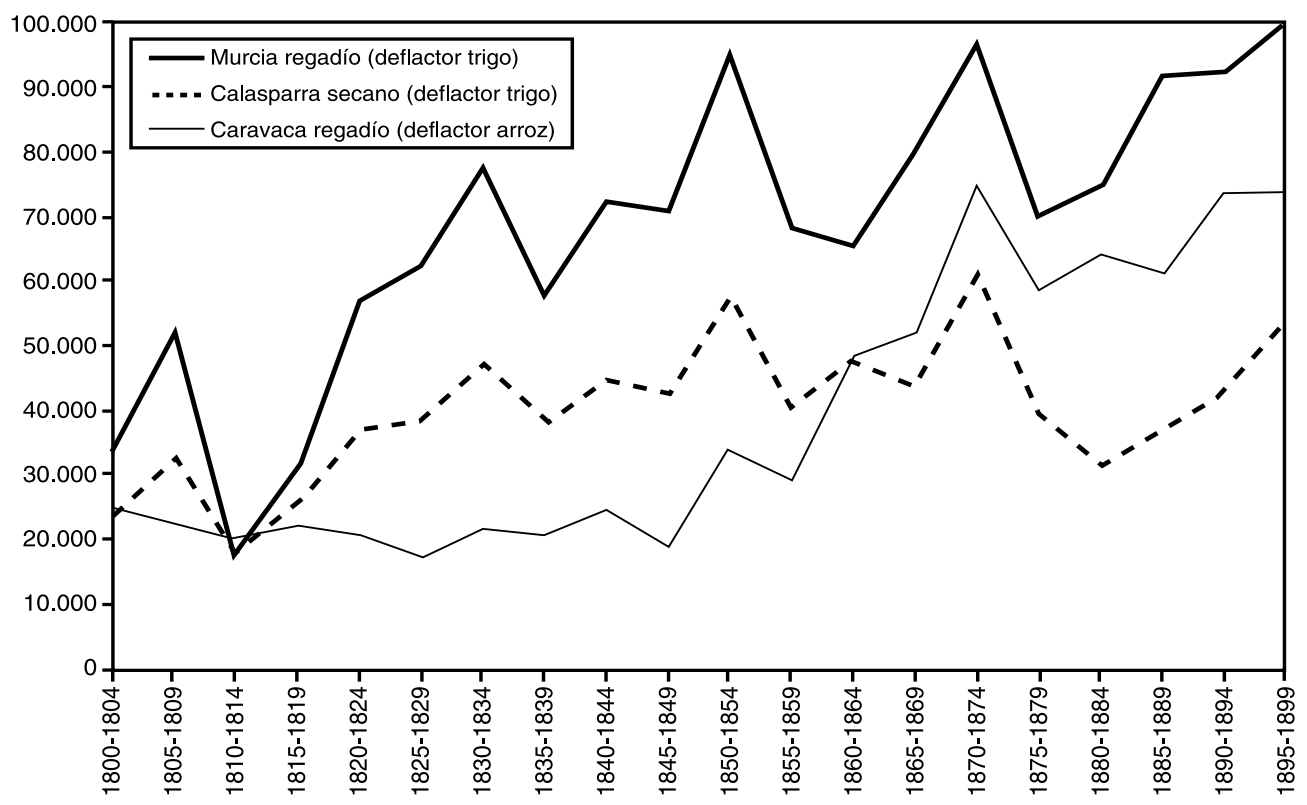

Arrendamientos en dinero. Renta neta = renta bruta descontando la carga fiscal.

Fuente: Archivo Municipal de Calasparra, Cuentas del conde del Valle de San Juan. Fondos de Murcia (Caja XX), Calasparra (Caja IV) y Caravaca (Caja VII).

b) 1820/1830-1875/1880. La tendencia de esta etapa es netamente alcista, aunque, ni el punto de partida ni el ritmo, sean los mismos en las tres áreas consideradas. En Caravaca y Murcia, más precoces, la subida de la renta precede a la de los precios. Ello se debe, en el caso de la primera, al aumento de la superficie cultivada en las propiedades rústicas (las reiteradamente citadas roturaciones) y, en el de la segunda, a la recuperación de la sericicultura, a la presencia paulatina en las rotaciones de aprovechamientos orientados al mercado (el pimiento para pimentón) y a la fragmentación de las explotaciones. En cuanto a Calasparra, la abrupta subida de las cifras a partir de 1845-1850 se relaciona con el fuerte aumento de la producción conseguida gracias a la introducción de abonos químicos. En Valencia tuvo lugar un fenómeno similar ${ }^{33}$. 
c) 1880-1900. Aunque en Europa son los años de la Gran Depresión finisecular, el impacto de la misma en Murcia sólo reviste cierta importancia en la década de 1880. Robledo (1984) ha observado idéntica evolución en Casti1la. Los efectos del fenómeno fueron algo más acusados en las áreas cerealistas - Caravaca - y muy moderados en las de regadío, debido a los progresos de la hortofruticultura. Sin olvidar que, al igual que en otras zonas de la España rural, el mercado de tierra arrendable estaba controlado por una élite de grandes propietarios locales muy poderosos.

Se puede concluir este apartado destacando que el nivel de movilidad alcanzado por la circulación de la tierra en Murcia superó al conseguido en aquellas áreas donde se han cuantificado compraventas a medio o largo plazo (Sevilla, Granada y el campo de Cariñena). Como casi en todas partes, además, la participación en el mercado conllevó ventajas para unos y riesgos para otros. Por un lado, se produjo el afianzamiento patrimonial de los más solventes, y se consolidó una nueva élite de empresarios agrícolas de procedencia social variopinta. Por otro, se reforzó la explotación familiar. Tal vez sea el último de estos fenómenos el que tuvo mayor alcance, tanto en la fisonomía de los mercados de trabajo y capital como en el ritmo del progreso técnico.

\section{El mercado de trabajo}

Algunas de las peculiaridades del mercado de trabajo han ido apareciendo al estudiar el de la tierra. Desde el punto de vista de la demanda, destaca la preferencia de los empleadores - los terratenientes- por la gestión indirecta de sus fincas frente a la posibilidad de explotarlas directamente mediante el recurso al empleo jornalero. Aparte de la herencia histórica, existían razones de peso que justificaron tal opción; en especial, las limitaciones ambientales y la dotación relativa de tierra y trabajo, ya apuntada en el apartado anterior. Respecto a las primeras, el bajo nivel de humedad había impuesto tradicionalmente en la mayor parte de la región un sistema de cultivo extensivo, el secano cerealista, caracterizado por los largos barbechos y la obtención anual de cosechas solamente en un tercio de la extensión superficial de las fin$\operatorname{cas}^{34}$; a mayor abundamiento, las fluctuaciones interanuales de pluviosidad convertían la obtención de las preciadas gramíneas en un "cultivo lotería". Ello generaba una fuerte irregularidad en las necesidades de trabajo debido a la sucesión de tiempos muertos y "puntas" a lo largo del año, con la particularidad de que, durante estas últimas, la necesidad de mano de obra era perentoria.

34 Normalmente, la superficie dedicada a cereales se dividía en tercios y se iba rotando el cultivo. En algunas zonas, como Moratalla o el altiplano de Jumilla-Yecla, se dejaba descansar la tierra hasta 8 ó 10 años. 
En tales condiciones, ¿cómo arreglárselas para mantener in situ una población que sólo percibía retribuciones unos 120-130 días al año? La respuesta de los propietarios consistió, históricamente, en restringir la movilidad de la misma "atándola" mediante la cesión de pequeñas parcelas, que oscilaban entre 5 y 10-12 hectáreas. Los titulares de grandes fincas solían, además, asegurar el domicilio a sus aparceros en las inmediaciones del edificio principal, domicilio por el que abonaban un pequeño censo. De esta manera, no sólo podían disponer de la capacidad de trabajo de los campesinos a lo largo de todo el año, sino imponerles unas restricciones que no hubieran aceptado de tratarse de asalariados. Los contratos obligaban a no iniciar las tareas de recolección de sus propias explotaciones hasta que no estuviera recogida y trillada la mies del "amo", a poner al servicio de las necesidades del mismo los animales de tiro - entre otras cosas, con el fin de acarrear los frutos a su domicilio-, y a plantar un número determinado de árboles. Todo lo cual aseguraba, a la vez, la reproducción física de la fuerza de trabajo, su presencia a lo largo de todo el año y su sumisión ${ }^{35}$.

Respecto a los regadíos del Segura, aunque el peso de los condicionamientos climáticos fuese menor, su influencia era todavía considerable en el siglo XIX. Hasta la expansión de la gran hidráulica en las primeras décadas de la siguiente centuria, el nivel de intensificación de los cultivos siguió siendo moderado a causa del régimen irregular que caracterizaba al precitado eje fluvial. La necesidad de trabajo era más elevada que en los espacios de secano, pero la estacionalidad y las fluctuaciones cíclicas seguían existiendo. Si los colonos salían mejor librados que los aparceros del secano no se debía a que recibiesen un trato mejor, sino al carácter periurbano de las huertas, con la consiguiente proximidad de los mercados de productos frescos y de otras ocupaciones retribuidas.

El hecho de que la reproducción de la fuerza de trabajo no dependiera exclusivamente de remuneraciones monetarias hubo de influir en la cuantía de las mismas. Hace algunos años elaboré una serie de salarios agrícolas del siglo XIX a base de remuneraciones medias, obtenidas a partir de lo abonado en diferentes tipos de trabajos (Pérez Picazo, 1990b). En ella se excluyeron las faenas extraordinarias, especialmente la siega, la trilla y la vendimia, porque el jornal percibido podía llegar a triplicarse, elevando artificialmente el promedio. Las cifras se refieren a tareas de peón más o menos especializadas: cerealicultura (labranza, siembra, escarda), arboricultura y/o viticultura, transporte, mantenimiento de la infraestructura de regadío, medición de frutos, etc. (Cuadro 5). 


\section{CUADRO 5}

EVOLUCIÓN DE LOS SALARIOS NOMINALES Y REALES EN MURCIA, 1800-1902,

(medias provinciales)

\begin{tabular}{lccccc}
\hline Decenios & $\begin{array}{c}\text { Salarios nominales } \\
\text { (reales) }\end{array}$ & Índices & $\begin{array}{c}\text { Salarios reales } \\
\text { (Kgs de pan) }\end{array}$ & Índices & $\begin{array}{c}\text { Precio pan } \\
\text { (reales/kg) }\end{array}$ \\
\hline $\mathbf{1 8 0 6 - 1 8 1 7}$ & 5,13 & 145,3 & - & - & - \\
$\mathbf{1 8 1 8 - 1 8 2 7}$ & 3,53 & 100,0 & 4,31 & 100,0 & 0,82 \\
$\mathbf{1 8 2 8 - 1 8 3 7}$ & 3,59 & 101,7 & 4,66 & 108,1 & 0,77 \\
$\mathbf{1 8 3 8 - 1 8 4 7}$ & 3,87 & 109,6 & 4,34 & 100,7 & 0,89 \\
$\mathbf{1 8 4 8 - 1 8 5 7}$ & 4,36 & 123,5 & 3,94 & 91,4 & 1,10 \\
$\mathbf{1 8 5 8 - 1 8 6 7}$ & 5,25 & 148,7 & 3,80 & 88,2 & 1,38 \\
$\mathbf{1 8 6 8 - 1 8 7 7}$ & 5,60 & 158,6 & 4,02 & 93,3 & 1,39 \\
$\mathbf{1 8 7 8 - 1 8 8 7}$ & 5,80 & 164,3 & 4,49 & 104,2 & 1,29 \\
$\mathbf{1 8 8 8 - 1 8 9 7}$ & 5,99 & 169,7 & 5,11 & 118,6 & 1,17 \\
$\mathbf{1 8 9 8 - 1 9 0 7}$ & 6,36 & 180,2 & 4,67 & 108,4 & 1,36 \\
\hline
\end{tabular}

Se ha utilizado como deflactor para calcular los salarios reales el precio del pan.

Fuentes: Contabilidades privadas de los condes del Valle de San Juan (Archivo Municipal de Calasparra, Fondos de Murcia, Cajas XV, XVI y XVII)) y de San Julián (Archivo privado). Actas Capitulares de Murcia y Lorca (Archivos Históricos Municipales de Murcia y Lorca). No están clasificadas como legajos.

El rasgo más visible de la evolución secular es la estabilidad, consecuencia directa del carácter moderado de las fluctuaciones -el balance es negativo si se comparan los salarios rurales murcianos con los catalanes o los navarros-; basta con señalar al respecto que, en el transcurso de todo un siglo, los salarios nominales tan sólo se incrementaron en poco más de un real. El fuerte desnivel existente entre 1806-1817 y 1818-1827 se puede atribuir, en mi opinión, a la interrupción de las exportaciones, que contrajo la demanda de trabajo en una época de crisis generalizada.

En cuanto a los salarios reales, su lenta evolución sitúa a Murcia dentro de la tónica general del país y la aleja de la descrita por la mayor parte de los de su entorno (O'Rourke y Williamson, 1997) ${ }^{36}$. Obsérvese la presencia de dos fluctuaciones al alza (1818-1838/43 y 1873-1902), separadas por treinta años de retroceso más o menos pronunciado (1844/47-1873). El movimiento de precios de los cereales - y, 
por consiguiente, del pan- fue decisivo en las tres etapas, aunque el deterioro de la fase intermedia se viera potenciado por el fuerte impulso de la renta de la tierra. A. M. Bernal apunta en el mismo sentido cuando señala que, hacia mediados de siglo, el descenso de los salarios reales resulta incuestionable ${ }^{37}$.

La estabilidad salarial se detecta igualmente en las remuneraciones de los trabajadores fijos (encargados, criados, pastores, muleros y guardas). Todos ellos disfrutaban de retribuciones mixtas, es decir, parte en dinero y parte en especie. Tal era el caso del labrador de "aniaga", más o menos equivalente a un encargado, que dirigía el cultivo en la parte de la explotación llevada directamente por el propietario y controlaba a los aparceros, percibiendo por sus tareas una soldada anual que osciló entre 600-700 reales, grosso modo, entre las décadas centrales y finales del XIX, amén de la vivienda. Compárese estas cifras con los 1.460 reales que cobraba en Navarra el sobrestante, figura similar a la indicada, según datos de Lana Berasain ${ }^{38}$. Los demás trabajadores, aparte de estar mantenidos y alojados, su jornal era inferior al de los eventuales y, en cuanto a los criados menores de edad, sólo tenían derecho a la manutención ${ }^{39}$.

La serie que presento requiere alguna explicación adicional. Recordemos, para empezar, que la rigidez de los salarios nominales se dio en la mayor parte de España; la curva de salarios agrícolas elaborada por Garrabou para Cataluña presenta una fisonomía similar (Garrabou, 1987, pp. 350-351). Una de las causas del fenómeno reside en el hecho de que, durante la mayor parte del siglo XIX, se siguió fijando la cuantía de los mismos en numerosos municipios por la fuerza de la costumbre, pese a que ya en 1767 se había promulgado un decreto que ponía fin a su regulación institucional. De ahí que se dieran coincidencias interregionales en lo referente al ritmo, aunque el montante presente algunas divergencias; Lana Berasain así lo ha comprobado al comparar los datos de Murcia con los de Barcelona, Lleida y Navarra (Lana Berasain, 2002, p. 215).

La inferioridad relativa de los salarios murcianos responde, asimismo, al descenso del coeficiente de intensidad industrial. Si tomamos como base 100 el conjunto español, el índice que mide el movimiento de la magnitud en cuestión era más elevado en 1850 que en 1900 -120 y 51 respectivamente (Zapata, 2001, p. 579)—. Murcia atravesó en la segunda mitad del siglo XIX un proceso que Nadal describió en términos de "desindustrialización", aunque en realidad se trate de una reconversión en Cataluña (2002).

38 Se trataba de un criado fijo de confianza encargado de dirigir y vigilar la fuerza de trabajo contratada. Lana Berasain (2002), p. 215.

39 El antropólogo Frigolé ha publicado una descripción escalofriante sobre las condiciones del trabajo infantil en las grandes fincas en las primeras décadas del siglo XX. Frigolé (1998). 
(Nadal, 1987). Un proceso caracterizado por el hundimiento de determinadas especialidades "viejas", como el textil, y por la emergencia de otras "nuevas", pertenecientes al subsector agroalimentario, que no cobraron fuerza hasta los años 18901900 (Pérez Picazo, 1990c, p. 315). De ahí el amplio predominio de los activos agrarios, que representaban el 71,4 por 100 del total en 1870 y el 79,9 en 1900 (72,1 y 73,5 por 100 , respectivamente, a escala nacional $)^{40}$, cuyo peso creciente contribuyó a erosionar las retribuciones.

Pasando a los rasgos de la oferta, podríamos resumirlas en tres: carácter mixto de los ingresos de los trabajadores, empeoramiento de su nivel de vida hasta finales de XIX y reforzamiento de los efectivos poblacionales.

La compleja composición de las retribuciones refleja las opciones de los ofertantes de empleo, ya descritas. Las declaraciones juradas elaboradas durante la primera mitad de la indicada centuria y/o los padrones de vecinos confeccionados con cierta regularidad desde 1856, resultan sumamente instructivos sobre las pautas laborales de las familias ${ }^{41}$. El reparto de tareas más extendido atribuye al padre las profesiones de propietario, arrendatario o jornalero (incluso de dos a la vez); a la madre, diversas formas de servicio doméstico y/o la venta en el mercado semanal de productos de la huerta o del gallinero; a los hijos adultos, la de jornaleros; y a los niños, desde edades variables, la de "criados" en alguna hacienda. Hacia 1860-1870 comienzan a detectarse, pero muy lentamente, ciertos cambios en el trabajo femenino relacionados con el desarrollo de las hilanderías de seda, las fábricas hijuela y la elaboración de pimentón.

En lo concerniente al descenso del nivel de vida, las pequeñas mejoras experimentadas por los salarios reales en las fases alcistas no fueron suficientes para contrapesar el fuerte deterioro sufrido en las décadas centrales del siglo XIX. Martínez Carrión ha mostrado el alcance del fenómeno utilizando un indicador biológico, la estatura, que no sólo baja en las precitadas décadas (hasta los años 1880), sino que lo hace con mayor intensidad en las áreas rurales que en las urbanas, y entre los campesinos con poca tierra que entre los mejor dotados ${ }^{42}$. Un rápido repaso de los hechos puede contribuir a explicar el fenómeno: a) empequeñecimiento de la unidad de cultivo; b) expansión de la cerealicultura en tierras marginales, que no tardó en verse afectada por la ley de rendimientos decrecientes; c) empeoramiento de la dieta campesina ${ }^{43}$, debido a la necesidad de desviar al mercado mayores proporciones de alimentos con el fin de aumentar la liquidez; y d) endeudamiento producido por un

\footnotetext{
40 Para Murcia, Martínez Carrión (2002a), p. 73. Para España, Zapata (2001), p. 568.

41 Padrones de Riqueza y Declaraciones Juradas de 1816, 1823, 1834 y 1840. Archivos Municipales de Murcia y Lorca.

42 Martínez Carrión y Pérez Castejón (2002), pp. 432-437.

43 Simpson llamó la atención en su momento sobre la pobreza del consumo alimenticio en España (1997).
} 
CUADRO 6

LA EVOLUCIÓN DE LA POBLACIÓN MURCIANA, 1797-1900

\begin{tabular}{lcccc}
\hline Años & Habitantes & $\begin{array}{c}\text { Porcentaje de la } \\
\text { población española }\end{array}$ & $\begin{array}{c}\text { Tasa de crecimiento } \\
\text { intercensal, España (\%) }\end{array}$ & $\begin{array}{c}\text { Tasa de crecimiento } \\
\text { intercensal, Murcia (\%) }\end{array}$ \\
\hline $\mathbf{1 7 9 7}$ & 256.641 & 2,76 & - & - \\
$\mathbf{1 8 5 7}$ & 380.969 & 2,47 & 0,64 & 0,45 \\
$\mathbf{1 9 0 0}$ & 577.987 & 3,11 & 0,45 & 1,26 \\
\hline
\end{tabular}

Fuente: Censos de Población. Ver Bibliografía.

incremento de la renta superior al de los salarios y por la adquisición de insumos. No parece desacertado plantearse la existencia de alguna relación entre una situación como la descrita y el estancamiento de la productividad del trabajo (Simpson, 1997; Gutiérrez Bringas, 2000). Ni siquiera la demanda de trabajo en las minas, donde se desarrollaban tareas duras y mal retribuidas según todos los testimonios, pudo contrarrestar la involución.

El contexto demográfico alcista, que multiplicaba los candidatos en los momentos "punta" del ciclo agrícola y en el mercado de explotaciones arrendables, constituye un último elemento a considerar (Cuadro 6). Tanto más cuanto que coincidió con una redistribución de los efectivos poblacionales presidida por la ruralización, apenas neutralizada por la emigración a Argelia — de escasa entidad $^{44}$ - , y estimulada por la crisis industrial. Mientras que en la mayor parte de los países europeos despegaba el éxodo rural, en 1857 un 55,5 por 100 de los murcianos vivían dispersos en cortijadas, pequeños pueblos y núcleos inferiores a los 5.000 habitantes. En 1900, el porcentaje era del 70 por 100. Ello no redundó, además, en la formación de nuevos municipios dotados de recursos propios y suficientes, dado que las reformas liberales mantuvieron la estructura administrativa del Antiguo Régimen, apoyada en el gran municipio ${ }^{45}$. Huelga decir que, en estas condiciones, las pautas de consumo y ocio mayoritarias iban a ser las propias de las sociedades rurales.

44 El contingente murciano supuso un 8,5 por 100 del total nacional, muy por detrás de Alicante y Almería, Vilar, Bel Adell y Gómez Fiaren (1999).

45 En la actualidad, la extensión media de los 45 términos municipales $\left(251,42 \mathrm{~km}^{2}\right)$ sigue siendo superior a la española $\left(62,7 \mathrm{~km}^{2}\right)$. 
Una situación como la descrita hubo de repercutir negativamente en la tasa de formación de capital humano, cuya influencia determinante en los procesos de crecimiento económico parece indiscutible. En el último trabajo de Lindert (2003), se reinterpretan los modelos de crecimiento de diversos países a la luz de la inversión pública realizada en la enseñanza primaria. Los resultados obtenidos contribuyen, en su opinión, a explicar el ritmo y las modalidades de los distintos procesos. Al igual que en el conjunto de España, el gasto de las instancias de poder local murcianas - los ayuntamientos- disminuyó a partir de la desaparición de los bienes de propios; sin olvidar las dificultades que planteaba hacer llegar la oferta educativa a una población no sólo dispersa, sino también distante del "lugar central", debido al gran tamaño de los términos municipales. Según los cálculos de Bernal (2002, p. 236), las regiones más desfavorecidas al respecto fueron Murcia, Extremadura y Andalucía. De ahí que la cuantía de la tasa de alfabetización de la primera quedase por debajo de la media española durante el período considerado: en 1860, dichas tasas ascendían al 17 y 26 por 100, respectivamente, y en 1900, al 29 y 43 por 100 (Núñez, 1992).

Conviene tener en cuenta, por último, que la demanda de trabajo fuera de las explotaciones familiares no exigía a sus titulares habilidades distintas a las que aplicaban en sus propias tierras, dado el lento desarrollo de la mecanización. Hasta las primeras décadas del siglo $\mathrm{XX}$, las actividades agrarias fueron intensivas en trabajo y no en capital; la dotación relativa de ambos factores de producción hacía poco rentable, como veremos, el cambio tecnológico.

Resumiendo, la forma en que se articula el mercado de trabajo en la región murciana parece tener un papel ambivalente en el proceso de crecimiento. El protagonismo de las explotaciones campesinas - entendidas como unidades de producción y consumo - facilitó, por un lado, la reconversión de cultivos y, por otro, la penetración del capitalismo a través de la monetización de la economía y de la acumulación de capital físico por parte del colectivo propietario. Pero, a la vez, ralentizó la acumulación de capital humano. Ello resultó determinante en la evolución de la productividad del trabajo, variable difícil de calcular, aunque los escasos datos que aportan las contabilidades privadas parecen apuntar hacia un estancamiento de las cifras. Una situación como la descrita hubo de generar, sobre todo, importantes restricciones desde el punto de vista de las demandas de capital y de productos manufacturados. 


\section{El mercado de capital}

Los progresos experimentados por la investigación sobre el mercado de capital en la agricultura durante las décadas de 1980 y $1990^{46}$ han despejado numerosas incógnitas que flotaban sobre el tema pero, sobre todo, nos han permitido rechazar la extendida hipótesis según la cual el crédito agrario, pieza esencial de aquél, no habría cobrado carta de naturaleza hasta bien avanzado el siglo XX. En un libro reciente, Postel-Vinay (1998, pp. 10-11) pone sobre el tapete la estrecha relación existente entre dicha hipótesis y el debate general sobre el papel desempeñado por las instituciones crediticias en el crecimiento económico. El historiador francés se adhiere a la idea de que el crédito se habría desarrollado como respuesta a los cambios habidos en el sistema productivo, y no como un condicionamiento previo de los mismos. Lo cual supone, obviamente, privilegiar el análisis desde el punto de vista de la demanda.

¿Cuáles fueron los principales condicionamientos de esta última en el caso murciano? Dos destacan entre ellos:

1) Las estructuras de la explotación y del poblamiento, cuyas fisonomías contribuyeron a desarrollar una demanda de fondos muy dispersa, donde predominaban unos prestatarios numerosos pero cuyas necesidades monetarias per capita eran reducidas. Ello propició la expansión de los mercados informales de crédito, cuyos representantes solían estar arraigados localmente, con el conocimiento consiguiente de la clientela potencial. Los costes de transacción de las operaciones resultaban así más bajos, ya que los agentes económicos en cuestión solían poseer un capital de información sobre sus vecinos que les permitía calcular la cuantía de los préstamos que podían concederse, tanto en función de la situación económica de cada uno de ellos como de su "moralidad". De esta manera, conseguían reducir el nivel de riesgo. Estamos, por tanto, ante una de las causas, según Martínez Soto (2001, pp. 186-187), del lento desarrollo de las instituciones propias del mercado formal.

2) La circunstancia de que las mayores necesidades de capital se diesen en las actividades económicas ligadas a los nuevos productos vectores, los minero-metalúrgicos, primero, y los hortofrutícolas más tarde. Dado su despegue sucesivo, sólo constituyeron alternativas de inversión en dos momentos: durante el boom minero de los años 1840 y durante la crisis de reconversión finisecular del mismo. El primero coincide con la oferta masiva de bienes raíces procedentes de la Desamortización y la Desvinculación; de hecho, se detecta un descenso de las 
compraventas, especialmente en Lorca, debido a su inserción en el área de influencia de Sierra Almagrera ${ }^{47}$, y un ascenso simultáneo de las escrituras de préstamo cuyo objetivo era la compra de acciones de las sociedades mineras o la participación en las fundiciones (Gráfico 4). En cuanto al segundo, los dos sectores se convierten en demandantes de fondos en las últimas décadas del siglo XIX. Los avances tecnológicos en la extracción de minerales y en las fábricas de fundición requerían una cuota de inversión más elevada, propia del contexto oligopólico del capitalismo, y, por su parte, el ciclo agrícola exigía mayores gastos (insumos, obras de regadío, plantaciones). La opción de los agentes económicos a favor de la expansión hortofrutícola e industrias derivadas tuvo muy en cuenta dónde era mayor la posibilidad de beneficio a corto plazo y cuál podría ser el coste de oportunidad. Aunque las tesis de Nadal contribuyeron, en su momento, a la formulación de hipótesis negativas sobre el impacto de la estrategia inversora en el crecimiento económico en Murcia, hoy estamos en condiciones de afirmar que la nueva agricultura y el conglomerado de actividades manufactureras ligado a ella, constituían una alternativa mejor adaptada que la metalurgia a la dotación de factores y de recursos naturales de la región. Las primeras eran intensivas en trabajo y no en capital, al contrario de lo que sucedía en la segunda, que también lo era en tecnología avanzada, en mano de obra especializada y en consumo energético. Para esta última había llegado el momento de recurrir al capital extranjero.

También resultó determinante en la toma de decisiones la evolución de la renta de la tierra, puesto que, desde la óptica financiera, una parte variable de la cantidad pagada como alquiler de la finca remuneraba el capital incorporado a la misma debido a inversiones anteriores. En el contexto económico de la región estudiada, parece claro que esa remuneración era mayor en el sector agrario que en los restantes, no sólo por la expansión del nuevo ciclo agrícola, sino porque las inversiones en infraestructuras hidráulicas estaban amortizadas hacía mucho tiempo y porque exis-tían múltiples mecanismos para incrementar la cuantía de la renta. El fabricante de chocolate José Monassot lo deja muy claro en el acta notarial en la que estipula la recepción de un préstamo mercantil de 50.000 reales por el comerciante Martín Torres Casanova, destinado a la adquisición de materias primas: "[...] aunque no carezco de dicho capital, dedicado como estoy a la industria agrícola, necesito grandes recursos para atender a las mejoras de fincas [...] lo que a mi juicio ha de proporcionarme mayores ventajas" 48 .

\footnotetext{
$47 \quad$ Pérez Picazo y Pérez de Perceval (2004), p. 66.

48 Establecimiento de un crédito mercantil garantizado con hipoteca, 14 de febrero de 1866, Notario Juan de la Cierva y Soto, legajo 10.054, p. 467. Archivo Histórico de Murcia.
} 
Pasando a las características de la oferta, no se ha insistido bastante en la intensidad y la complejidad que presenta el crédito agrario en este período, tanto en Murcia como en otras regiones, entre otras razones, por la dificultad que presenta la reconstrucción del complejo entramado de relaciones que existían entre los mercados formal e informal de capitales. Este hecho ha impulsado a PostelVinay (1999, p.35) a afirmar que, aun en los casos en que la práctica del crédito está diseminada en las zonas rurales, si presenta formas diversificadas y, sobre todo, si se inserta en redes de intermediarios organizadas desde un centro urbano, no siempre se le debe subsumir bajo la etiqueta de la usura.

Los organismos de crédito mostraban una estructura piramidal. La base, constituida por prestamistas modestos, se apoyaba en las áreas rurales, aunque a medida que avanza la segunda mitad de la centuria comienza a ampliarse hacia núcleos de población mayores. En cuanto a la cúspide, estaba formada por una minoría de establecimientos comerciales instalados en los únicos centros urbanos propiamente dichos de la región, Murcia, Cartagena y Lorca, que, de forma especializada o no, habían convertido el crédito en un negocio. En posición intermedia entre ambos grupos queda un sector, también urbano, que no maneja capitales propios y cuyos miembros son denominados "especuladores" en los padrones de vecinos. Se trata de intermediarios stricto sensu, que recibían dinero líquido a un interés bajo (el 6 por 100) de algunos bancos de Madrid - como el de San Carlos, a finales del siglo XVIII, y los de San Fernando e Isabel II en el XIX-, o de organismos de crédito regionales, y lo prestaban al 12 por 100 . Oficialmente, a particulares, pero en algunas ocasiones también al colectivo de prestamistas rurales señalado más arriba. Presentes desde las últimas décadas del siglo XVIII, desaparecen de forma paulatina un siglo después.

Los prestamistas locales eran mayoritariamente vecinos de las zonas donde actuaban y el radio de las redes organizadas en torno a ellos raramente excedía los 20-25 kilómetros. Las cantidades prestadas solían ser reducidas y adelantadas a corto plazo; con ellas se financiaban operaciones repetitivas ligadas al trabajo en el campo (siembra y recolección de frutos) o se satisfacían las necesidades del consumo familiar de una cosecha a otra. En algunos aspectos, este tipo de transacciones no son otra cosa que una manifestación del viejo "sistema por adelantos". Por consiguiente, la contribución de las mismas a la difusión del crédito moderno fue escasa, aunque es indudable que su papel en la monetización de la economía rural no fue en absoluto desdeñable.

El mayor problema práctico que se nos plantea es la cuantificación, siquiera aproximada, del dinero líquido que circulaba por estos canales, sobre todo porque la mayor parte de las operaciones se verificaban oralmente y una parte desconocida de las mismas se evaluaba en especie. Lo que sabemos es de forma indirecta y global. La enorme extensión del sistema, que cubría como una red invisible el 
mundo rural, no deja lugar a dudas, por lo que su monto global debió ser considerable. Los inventarios post mortem de algunos individuos que ejercían esta actividad pueden proporcionarnos pistas sobre el alcance crematístico de las operaciones: de los cincuenta que he podido analizar entre 1820 y 1890, la cifra a la que ascendían las deudas pendientes osciló entre 10.000 y 30.000 pesetas hasta los años 1850, elevándose hasta 60.000 ó 70.000 después. El juicio de los contemporáneos era muy negativo: el calificativo de usurarias acompaña cualquier alusión a este tipo de operaciones, a causa de la enormidad de los intereses pagados, que podían alcanzar entre el 25 y el 50 por $100^{49}$; tanto más cuanto que la cuantía de los mismos se incrementaba a medida que las garantías del prestatario eran menores.

Hemos mencionado que la cúspide del negocio crediticio estaba ocupada por las casas de comercio al por mayor, a cuya ubicación urbana nos hemos referido igualmente. Su papel en el conjunto de la oferta bancaria es importante en las décadas centrales del XIX, como ha puesto de manifiesto, tanto para Asturias como para el conjunto español, García López (1987 y 1989). No se trata únicamente de créditos comerciales sino, sobre todo, de préstamos hipotecarios. Los inventarios llevados a cabo en los cinco establecimientos más importantes de la región ${ }^{50}$ muestran que la parte financiera del negocio representaba entre el 39,2 mínimo-y el 58,9 por 100 -máximo- del capital de la entidad. Dentro de la misma, además, el monto de los fondos colocados en el tipo de préstamo indicado ascendía a más de la mitad de los bienes muebles, elevándose en cifras absolutas a $2.145 .879,1.998 .564,1.562 .312,1.145 .870$ y 919.720 pesetas, respectivamente. Cuando, a partir de las décadas de 1860 y 1870, estos organismos fueron perdiendo protagonismo, su lugar fue ocupado por casas de banca especializadas ${ }^{51}$. Unos y otras cubrieron buena parte de las necesidades crematísticas del momento, lo que ayuda a entender el escaso desarrollo del aparato bancario hasta fechas tardías. Su inexistencia no debe describirse en términos de "subdesarrollo", sino de adaptación. De hecho, desempeñaron un importante papel en la divulgación de las modernas técnicas crediticias; en sus escrituras fundacionales especifican su dedicación al "giro y descuento de letras y pagarés, al préstamo hipotecario y a toda clase de operaciones mercantiles".

\footnotetext{
49 Ver las respuestas de los Sociedades Económicas de Amigos del País a la Encuesta Agrícola de 1849-1856 y los testimonios reunidos al respecto en la documentación existente sobre Murcia en la Crisis Agrícola y Pecuaria (Vol. IV, pp. 194-199 y 643-651). Referencia completa en Bibliografía.

50 Se trata, por orden de la cuantía económica de sus activos, de Servet-Brugarolas, Marín Baldo, y Damián Almansa (instaladas en Murcia), Bofarull (Cartagena) y Mención-Moyardo (Lorca).

51 En Murcia, destacan las de Casalins, Nolla, Martínez Ureta y, sobre todo, la de Eleuterio Peñafiel, cuyo establecimiento quebró y fue confiscado por el Banco de España en 1908.
} 
Dado que el préstamo hipotecario constituyó en Murcia un instrumento de crédito privilegiado, no parece ocioso dedicarle algún espacio, tanto más cuanto que la existencia de fuentes que permiten su cuantificación pone en nuestras manos un buen indicador sobre la coyuntura y la fisonomía del mercado de crédito. La comparación con las cifras nacionales demuestra, en efecto, la importante difusión del mismo. Entre 1850 y 1873, se llevaron a cabo en España 339.126 operaciones, mientras que en los cuatro partidos judiciales de Murcia sobre los que poseemos datos las cifras ascienden a 24.273 (el 7,2 por 100, porcentaje superior al que alcanzaba en este momento la población murciana sobre la nacional, un $2,5$ por 100$)^{52}$. La parte alícuota de los capitales prestados sobre el total, en cambio, es más modesta: 53 millones de pesetas, que representan el 2,1 por 100 de los 2.545 sumados por las operaciones en la totalidad del territorio español (Martínez Soto, 2001, p. 205). La importancia relativa de las cifras responde al modesto avance de la agricultura intensiva; en Almería, Sánchez Picón (2001, p. 178) detecta una tendencia similar en aquellas comarcas donde se estaba imponiendo el cultivo de la uva de mesa.

El aumento de la demanda contribuyó a hacer más onerosas las condiciones de la concesión de préstamos. La Junta Provincial de Agricultura resumía, en 1850, el problema como sigue: "no es fácil obtener dinero por hipoteca en esta provincia, pues el valor del aval ha de ser al menos un triple de la cantidad prestada, siendo el interés del 18 por 100 hasta el 25 por $100^{\prime \prime 3}$. Más adelante, la ley hipotecaria de 1863 suavizó las condiciones, y sus efectos fueron claramente perceptibles en la región murciana: los intereses se movieron a partir de entonces en la banda del 10-18 por 100, y los plazos de devolución tendieron a alargarse —en las décadas de 1870 y 1880 más del 60 por 100 de los demandantes consiguieron entre seis meses y tres años (Martínez Soto, 2001, pp. 205-210)—. Lo que no se suavizó fue el aval exigido antes de la entrega de la cantidad prestada.

Con el fin de verificar una aproximación más fina al mercado hipotecario, me he centrado en los dos partidos donde las datos son más abundantes y fiables, Murcia y Lorca (Cuadro 7 y Gráfico 2).

52 Se trata de Murcia, Lorca, Yecla y Caravaca. Las fuentes utilizadas son los libros del Registro Antiguo o Contaduría de Hipotecas, amén de los datos aportados por Martínez Soto para Yecla (2001), p. 202.

53 Respuesta de la Sociedad Económica de Amigos del País de Murcia al Interrogatorio formulado por R. O. del 15-VIII-1849. Martínez Soto (2001), p. 204. 
CUADRO 7

CUANTÍA DE LOS PRÉSTAMOS HIPOTECARIOS, 1800-1889

\begin{tabular}{lrrrr}
\hline & \multicolumn{2}{c}{ Murcia } & \multicolumn{2}{c}{ Lorca } \\
\hline Períodos & $N^{\circ}$ actas & Pesetas & $N^{\circ}$ Actas & Pesetas \\
\hline $\mathbf{1 8 0 0 - 1 8 3 6}$ & 184 & 235.471 & 50 & 61.408 \\
$\mathbf{1 8 3 7 - 1 8 6 2}$ & 1.777 & 8.003 .645 & 1.378 & 3.271 .302 \\
$\mathbf{1 8 6 3 - 1 8 9 0}$ & 4.206 & 18.123 .041 & 3.393 & 6.902 .792 \\
\hline
\end{tabular}

Fuente: Contaduría de Hipotecas, 1800-1862. Protocolos de Murcia y Lorca, 1863-1890. Ver Apéndice.

Obsérvese que la trayectoria de las operaciones recorre las mismas etapas que las de la renta:

1) 1800-1830/40. Más que una caída de las cifras, lo que se detecta es un prolongado estancamiento. Ello da fe de la escasa o nula confianza que inspiraba el poder político, imprescindible para el desarrollo del crédito, y del descenso de la inyección de dinero líquido en la economía regional. La circulación monetaria se ralentizó de tal forma que, en 1823, un conocido comerciante de la capital escribía "muchas veces no hay caudales para hacer surtidos en tiempo y forma" 54 .

2) 1830/1840-1870/74. El crecimiento de las operaciones se hace evidente, aunque su ritmo sea inferior al de la subida de la renta. Varios factores debieron contribuir al cambio de tendencia: el relanzamiento de la actividad económica, la recuperación de la confianza tras la consolidación del régimen liberal y la promulgación de la nueva legislación hipotecaria de 1863 (y los retoques de 1868), que permitieron salir a la luz pública a numerosos prestamistas.

3) 1870/74-1885/1890. Tras el máximo de 1865-1869, se produce un lento declive, más pronunciado en el caso de Lorca. En mi opinión, ello tuvo que ver con el descenso de la demanda de crédito por parte de los agricultores modestos, que se beneficiaron del aumento de los salarios reales y de la ralentización del movimiento alcista de la renta.

54 Expediente de quiebra. Escribano S. Fernández de Laguna, 1823, legajo 5.020, p. 20. Archivo Histórico Provincial de Murcia. 


\section{GRÁFICO 2}

MOVIMIENTO DE LOS CRÉDITOS HIPOTECARIOS EN MURCIA Y LORCA, 1800-1889

(medias quinquenales, en pesetas de 1800)

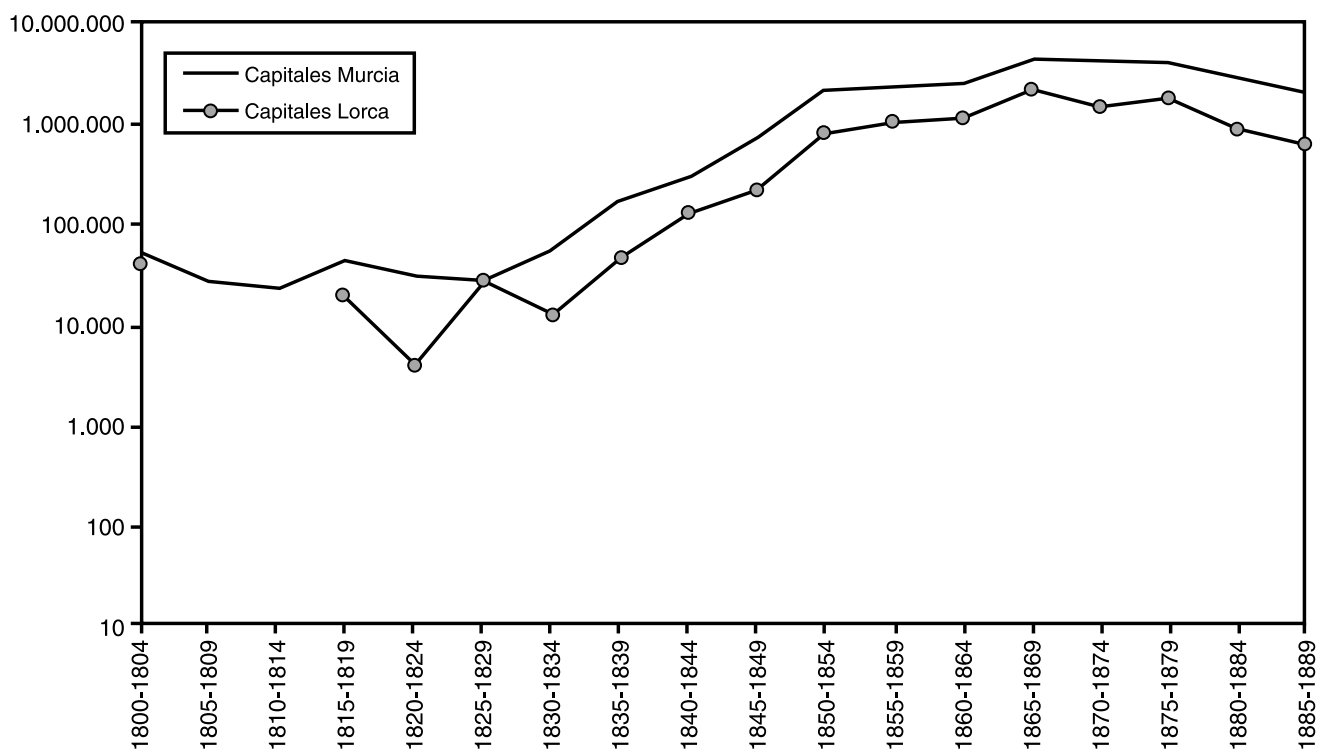

Fuentes: las mismas del Cuadro 7.

¿Cuál fue la distribución social y el destino de los capitales ofertados? La fuente que estamos utilizando permite responder a ambas preguntas. Hay pocas sorpresas en lo concerniente al primer punto: los receptores de fondos procedían mayoritariamente de los mismos grupos que figuraron en cabeza en el movimiento de compraventas de tierra: las clases medias urbanas y rurales (Gráfico 3). La débil presencia de los grandes terratenientes en las operaciones es atribuible a la facilidad de acceso de los miembros de dicho colectivo a los fondos del Banco Hipotecario y / o del Banco de España, cuya clientela se limitaba a los agentes sociales de mayor solvencia. El contacto con fuentes de financiación exógenas constituye así una exclusiva de este grupo social, compartida con la élite mercantil de la región, y en absoluto extensible a los prestatarios rurales. 


\section{GRÁFICO 3}

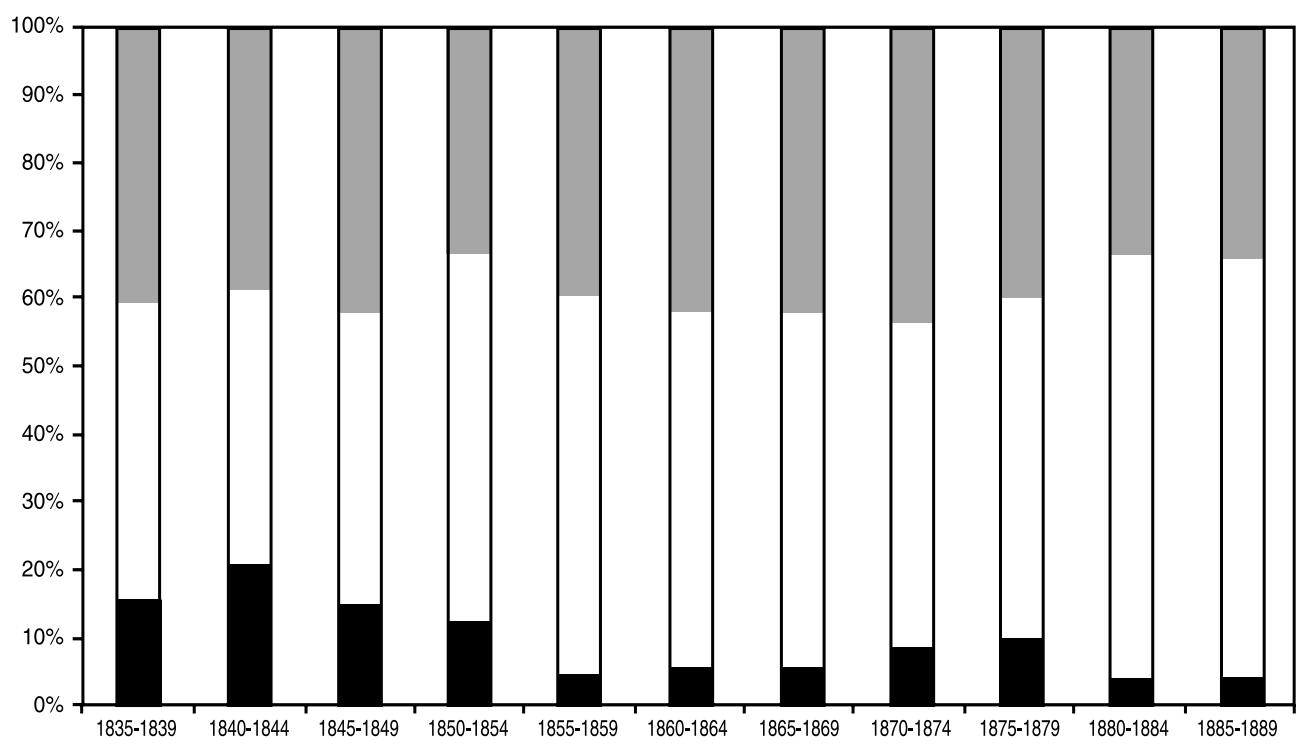

Grandes propietarios

口 Pequeños y medianos propietarios

․ Clases medias urbanas

Fuente: Contaduría de Hipotecas para el período 1836-1862 y Protocolos notariales de Murcia y Lorca para 1862-1874. Ver Apéndice.

La agricultura fue el destino mayoritario de los capitales prestados: lo absorbido por ella casi nunca baja de la mitad del total (Gráfico 4). Hasta los años 1860-1870, la compraventa de tierras se llevó la parte del león (el proceso desamortizador se encontraba en su momento culminante); después la inversión en mejoras toma el relevo. Unas veces se trata de adquisiciones modestas, como caballerías, algún útil de labranza, semillas, etc. Pero en otras el crédito solicitado es importante y su objetivo suele ser la expansión del nuevo ciclo agrícola: puesta en marcha de plantaciones de frutales y, sobre todo, verificación de obras dirigidas a la ampliación del regadío. Lo cual no obsta para que la tecnología hidráulica siga siendo la tradicional: construcción de boqueras en las ramblas, prospección de aguas subterráneas, implantación de artefactos elevadores (norias, motores), etc. (Calatayud y Martínez Carrión, 1999). 


\section{GRÁFICO 4}

DESTINO DE LOS CAPITALES PRESTADOS EN MURCIA Y LORCA, 1836-1890

(porcentajes)

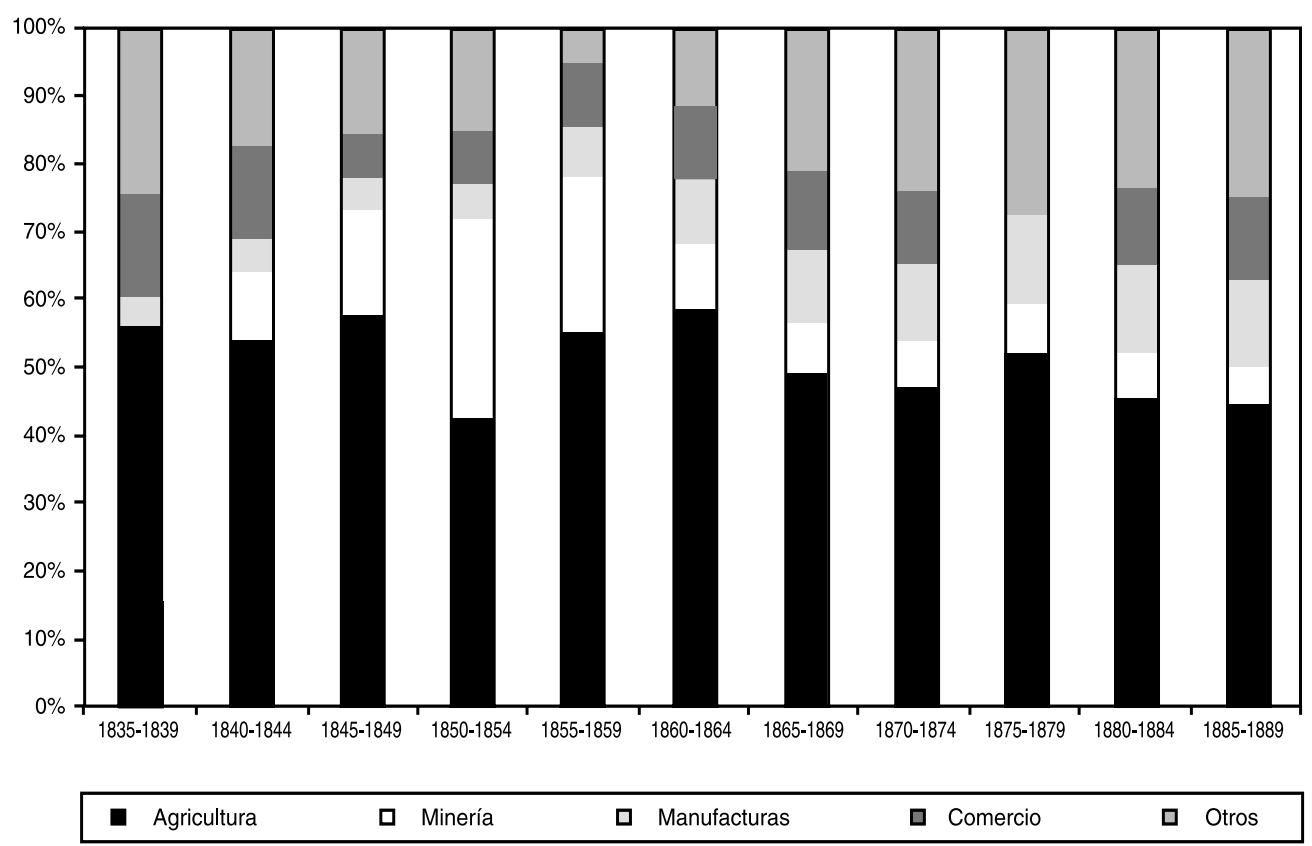

Fuente: Ver cuadro anterior.

A fines del siglo XIX, pues, el capital era el factor de producción cuya circulación se había incrementado con mayor lentitud y, obviamente, el más caro. El acceso al crédito en condiciones medianamente aceptables resultaba todavía difícil. La mayoría de los pequeños y medianos propietarios continuaron viéndose obligados a recurrir a los prestamistas locales hasta que surgieron las cooperativas de crédito en el siglo XX, fuera de los límites cronológicos de este trabajo. Incluso los agentes económicos que podían conseguir préstamos menos onerosos consideraban que el precio del dinero era excesivo; sus opciones, como se ha explicado a lo largo de estas páginas, tuvieron muy en cuenta este hecho. 


\section{Conclusiones}

La larga crisis con la que se inicia el siglo XIX deja abierto en Murcia un problema grave: el abastecimiento de una población cada vez más densa en una coyuntura negativa para los productos de exportación tradicionales. La respuesta inmediata, favorecida por las disposiciones liberalizadoras, consistió en la roturación de nuevas tierras y en el mantenimiento del cultivo del trigo en los regadíos. Buena estrategia si se tiene en cuenta que los nuevos productos susceptibles de comercializarse no adquirieron la categoría de tales hasta los años 1840-1860, en el caso de los minerales no ferrosos, y hasta las décadas finales de la centuria, en el de los hortofrutícolas. El descenso del nivel de extraversión en una economía históricamente muy abierta debilitó las actividades urbanas y contribuyó a la ruralización: los habitantes de los núcleos de población tendieron a instalarse allí donde la oferta de trabajo era mayor y el suministro de alimentos más fácil. El impacto negativo de un proceso de estas características ha sido suficientemente destacado.

¿Qué fisonomía adquieren los mercados de factores tras la revolución liberal? En lo que se refiere al de la tierra, el importante aumento de la oferta generó un vasto trasiego de propiedades. Ello dio lugar a un conjunto de transformaciones de gran calado, entre las que merecen ser destacadas la formación de una élite de propietarios bastante dinámica e integrada en la categoría media-alta, pero, sobre todo, el afianzamiento de la gestión indirecta bajo la forma de explotaciones familiares de reducidas dimensiones. Estas unidades de cultivo, ¿fueron capaces de generar unas condiciones óptimas que facilitaran el proceso de reconversión agrícola y el avance de la modernización? Pese a que la funcionalidad de las mismas se vio facilitada por su inserción en unas redes mercantiles muy extensas, que, por primera vez en la historia de Murcia, estuvieron controladas por agentes económicos oriundos de la región (Pérez Picazo, 2004), la respuesta es ambigua. En cualquier caso, parece innegable que a través de ellas se sentaron las bases de una agricultura intensiva y especializada, pero también que no propiciaron la acumulación de capital humano.

Las transformaciones del mercado de la tierra repercutieron en el de trabajo. Tanto la oferta como la demanda se caracterizaron en adelante por su carácter mixto, característica que contribuyó a la estabilidad salarial a la baja, acentuada por el hecho de que la posibilidad de encontrar empleo en los sectores secundario y terciario fuese cada vez más escasa. No se trata de un fenómeno excepcional: las investigaciones disponibles han confirmado el retroceso de los niveles de vida como un atributo generalizado de las primeras etapas del capitalismo. En estas condiciones, ¿cómo se adecuó desde el punto de vista de la demanda la abundante disponibilidad de mano de obra y su escasa preparación con las exigencias del cambio agrícola? Ya conocemos la respuesta: desarrollando sistemas intensivos en trabajo, con la consiguiente ralentización del progreso técnico. 
Por último, en lo relativo al mercado de capital, su nota fundamental a lo largo del siglo XIX consistió en el predominio del mercado informal sobre el formal; de ahí la tardía aparición de los organismos pertenecientes al primero y sus numerosos avatares: la fundación de un banco de emisión en 1863 —el Banco de Murcia- fracasa, el Banco de España no tuvo sucursal hasta 1884 y los capitales regionales no invirtieron en esta línea hasta 1902 — con la creación del Banco de Cartagena-. El dinero era el factor de producción más caro a finales del XIX, sobre todo para los propietarios modestos, y fue absorbido de forma mayoritaria por los agentes económicos más dinámicos - los nuevos propietarios y el colectivo mercantil-. Los fondos prestados se jugaron alternativamente a la carta minera y/o agraria, dejándose guiar por la dotación relativa de factores, o fueron colocados en la organización de redes comerciales.

En definitiva, ¿se produjo un aprovechamiento adecuado de los recursos naturales y humanos atendiendo a la tecnología disponible y a las condiciones ambientales? Creo, tras lo dicho, que se pude contestar afirmativamente, pero introduciendo numerosas salvedades. La existencia de un proceso de intensificación y especialización parece indudable, pero su ritmo fue muy lento. En ello influyeron, aparte de razones exógenas - la acción del Estado, que hasta el siglo XX no desarrolló una política de modernización del regadío-, otras claramente endógenas, como el predominio de la población rural, el descuido de los ayuntamientos en materias sanitarias y educativas, y la tremenda desigualdad en el reparto de la tierra y de los ingresos (por la vía de la renta). La suma de todas ellas generó un contexto poco favorable para un rápido crecimiento de la productividad del trabajo y para el aumento de la demanda, tanto de capital como de artículos manufacturados.

\section{Fuentes}

\section{Archivo Histórico Provincial de Murcia}

\section{Protocolos de Murcia}

Cascales Font, José (1870-1875). Legajos 10.020 a 10.032.

Cierva y Soto, Juan de la (1860-1899). Legajos 10.033 a 10.999. Serie intercalada por legajos de otros notarios que lo sustituyen de manera intermitente (ver lista).

Cano Cordero, Miguel (1860-1880). Legajos sueltos: 5.105 a 5109, 9.977 a 10.019, 11.151 a $11.158,11.719$ a 11.726 .

Gaya y Ansaldo, Román (1860-1876). Legajos sueltos: 10.095 a 10.106.

Herrera Martínez, Miguel (1861-1876): Legajos 11.012 a 11.034.

Manresa Calatayud, Pedro (1865-1883). Legajos sueltos: 10.135 a 10.150; 10.351 a 
10.356; 11.011 a $11.020 ; 11.023$ a 11.044.

Piñeyro y Coutiño, José (1862-1883): 10.201 a 10.358; 11.076 a 11.087.

Contaduría de Hipotecas de Murcia

Libros 2.142 a 2.433, años 1836-1862.

Contaduría de Hipotecas de Yecla-Jumilla

Libros 2.662 a 2.713, años 1836 a 1862.

Lorca. Archivo Histórico Municipal

Protocolos de Lorca

Alcázar Puche, Mariano (1859-1903). Legajos 2.044 a 2.170.

Alberola, Sebastián Ma (1860-1899). Legajos 2.205 a 2.270.

Pérez Fernández, Miguel (1863-1876). Legajos 2.325 a 2.355.

Romera López, Manuel (1854-1870). Legajos 2.287 a 2.302.

Rosique Pérez, Blas (1868-1893). Legajos 2.456 a 2.607.

Tomás, Andrés (1851-1872). Legajos 2.304 a 2.325.

Contaduría de Hipotecas de Lorca

Libros 13 a 75, años 1836 a 1862.

Censo de población de 1857. Boletín Oficial de la Provincia de Murcia.

Calasparra. Archivo Histórico Municipal

Contabilidad del Conde del Valle de San Juan. Sin clasificar. La numeración de las cajas es la que figura en los fondos depositados recientemente en el Archivo.

Fondos de Murcia, Cajas XV, XVI, XVII, XX, XXIII y XXIV.

Fondos de Calasparra: Caja IV.

Fondos de Caravaca: Caja III.

Caravaca. Archivo Municipal.

Libros de la Contaduría de Hipotecas. Depósito del Registro de la Propiedad de

Caravaca. Sin clasificar.

Archivo General de Simancas

Catastro de Ensenada, 1755, Dirección General de Rentas, libros 463 y 464.

\section{Bibliografía}

BERNAL, Antonio M. (1999): “La agricultura y la ganadería española en el siglo XIX”, en ANES, Gonzalo (ed.), Historia Económica de España, siglos XIX y XX, Barcelona, Crítica, pp. 83-185.

-(2002): “Innovación y cambio tecnológico en la agricultura andaluza contemporánea", en GONZÁLEZ DE MOLINA, Manuel (ed.), La Historia de Andalucía a debate. II El campo andaluz, Sevilla, Junta de Andalucía, pp. 225-249.

BERG, Maxine (1987): La era de las manufacturas, 1700-1820, Barcelona, Crítica. 
CALATAYUD, Salvador (2002): “Tierras inundadas. El cultivo del arroz en la España contemporánea (1880-1936)", Revista de Historia Económica, XX, 1, pp. 39-81.

CALATAYUD, Salvador, MILLÁN, Jesús, y ROMEO, María Cruz (2000): “El rentismo nobiliario en la agricultura valenciana del siglo XIX", Revista de Historia Económica, XVIII, 1, pp. 79-107.

CALATAYUD, Salvador, y MARTÍNEZ CARRIÓN, José Miguel (1999): “El cambio técnico en los sistemas de captación e impulsión de las aguas subterráneas para riego en la España mediterránea", en GARRABOU, Ramón, y NAREDO, José Manuel (eds.), El agua en los sistemas agrarios. Una perspectiva histórica, Madrid, Argentaria/Visor, pp. 15-39.

CARMONA PIDAL, Juan (2001): Aristocracia terrateniente y cambio técnico en la España del siglo XIX. La Casa de Alcañices (1790-1910), Valladolid, Junta de Castilla y León.

CARMONA PIDAL, Juan, y SIMPSON, James (1999): “The 'Rabassa Morta' in Catalan viticulture: the rise and decline of a long term sharecropping contract, 1670s1920s", The Journal of Economic History, 59-62, pp. 290-315.

-(2003): El laberinto de la agricultura española. Instituciones, contratos y organización entre 1850 y 1936, Zaragoza, Prensas Universitarias.

Censo de la población de España de 1797 executado por orden del Rey en el de 1801, Madrid, 1801, Imprenta de Vega y compañía, Madrid.

Censo de Población de 1900. Madrid, INE.

COLOMÉ, Josep (2000): “Pequeña explotación agrícola, reproducción de las unidades familiares campesinas y mercado de trabajo en la viticultura mediterránea del siglo XIX. El caso catalán", Revista de Historia Económica, XVIII, 2, pp. 281-307.

$L a$ crisis agrícola y pecuaria. Información escrita de la comisión creada por $R$. D. del 7 de julio de 1887 para estudiar la causa de la crisis por la que atraviesa la agricultura y la ganadería. Madrid, Establecimiento Tipográfico Sucesores de Rivadeneyra, 1888.

DERTILIS, Gerard (1992) y (1993): “Terre, paysans et pouvoir économique. Grèce, XVIII-XIXe siècles", Annales, 2, pp. 273-291 y 1, pp. 85-107.

DONÉZAR, Javier María (1984): Riqueza y propiedad en la Castilla del Antiguo Régimen. La provincia de Toledo en el siglo XVIII, Madrid, MAPA.

DOMÍNGUEZ, Rafael y GUIJARRO, Marta (2000): “Evolución de las disparidades espaciales del bienestar en España, 1860-1930. El Índice Físico de Calidad de Vida", Revista de Historia Económica, XVIII, 1, pp. 109-137.

DOMÍNGUEZ, Rafael (2002): La riqueza de las regiones. Las desigualdades económicas regionales en España, 1700-2000, Madrid, Alianza Editorial.

FERNÁNDEZ PRIETO, Lourenzo (2001): “Caminos del cambio tecnológico en las agriculturas españolas contemporáneas" en PUJOL, J. GONZÁLEZ DE MOLINA, M., FERNÁNDEZ PRIETO, L., GALLEGO, D., y GARRABOU, R., (eds.), El pozo de todos los males, Barcelona, Crítica, pp.95-147. 
FERRER, Amparo (1982): Paisaje y propiedad en la Tierra de Alhama (Granada). Siglos XVIII-XX, Granada, Diputación Provincial.

FRIGOLÉ, Joan (1997): Un hombre. Género, clase y cultura en el relato de un trabajador, Barcelona, Muchnik.

GALLEGO, Domingo (1998): “De la sociedad rural en la España contemporánea y del concepto de sociedad capitalista. Un ensayo", Historia Agraria, 16, pp. 13-55.

-(2001a): "Historia de un desarrollo pausado: integración mercantil y transformaciones productivas de la agricultura española (1800-1936)", en PUJOL, J., GONZÁLEZ DE MOLINA, M., FERNÁNDEZ PRIETO, L., GALLEGO, D., y GARRABOU, R., (eds.), El pozo de todos los males, Barcelona, Crítica, pp. 147-205.

-(2001b): "Sociedad, naturaleza y mercado: un análisis regional de los condicionantes de la producción agraria española (1880-1936)", Historia Agraria, 24, pp. 11-57.

GARCÍA LÓPEZ, José Ramón (1987): Los comerciantes banqueros en el sistema bancario español. Estudio de las casas de banca asturianas en el siglo XIX, Oviedo, Universidad de Oviedo.

-(1989): “El sistema bancario español del siglo XIX: ¿Una estructura dual? Nuevos planteamientos y nuevas propuestas", Revista de Historia Económica, VIII, 1, pp. 111-133.

GARRABOU, Ramón (1987): “Salarios y proletarización en la agricultura catalana de mediados del siglo XIX", Hacienda Pública Española, 108-109, pp. 343-361.

-(2001): "Crecimiento agrario, atraso y marco institucional", PUJOL, J., GONZÁLEZ DE MOLINA, M., FERNÁNDEZ PRIETO, L., GALLEGO, D., y GARRABOU, R., (eds.), El pozo de todos los males, Barcelona, Crítica, pp. 215-239.

GARRABOU, Ramón, PLANAS, Jordi, y SAGUER, Enric (2001): ¿Un capitalisme imposible? La gestió de la gran propietat agrària a la Catalunya contemporània, Vic, Eumo Editorial.

GARRABOU, Ramón, y TELLO, Enric (2002): “Salario como coste, salario como ingreso: el precio de los jornales agrícolas en la Cataluña contemporánea, 17271939”, en MARTÍNEZ CARRIÓN, José Miguel (ed.), El nivel de vida en al España rural, siglos XVIII-XX, Alicante, Publicaciones de la Universidad de Alicante, pp. 175-113.

GARRIDO, Samuel (2004): Canem gentil. L'evolució de les estructures agraries a la Plana de Castelló (1750-1930), Castellón, Ayuntamiento de Castellón.

GAVIGNAUD, Génevieve (1983): Propriétaires-viticulteurs en Rousillon. Structures, conjoncture, société, XVIIe-XIXe siécles, Paris, Publications de la Sorbonne.

GONZÁLEZ DE MOLINA, Manuel (2001): “Condicionamientos ambientales del crecimiento agrario español", en PUJOL, J., GONZÁLEZ DE MOLINA, M., FERNÁNDEZ PRIETO, L., GALLEGO, D., y GARRABOU, R., (eds.), El pozo de todos los males, Barcelona, Crítica, pp. 43-93 
GONZÁLEZ DE MOLINA, Manuel, y SEVILLA, Eduardo (1991):"Minifundio y gran propiedad agraria: estabilidad y cambio en la Alta Andalucía, 1758-1930", en SAAVEDRA, Pegerto, y VILLARES, Ramón (eds.), Señores y campesinos en la Península Ibérica, siglos XVIII-XX, 2, Barcelona, Crítica, pp. 88-139.

GRUPO DE ESTUDIOS DE HISTORIA RURAL (GEHR) (1991): Estadísticas históricas de la producción agraria española, 1859-1935, Madrid, MAPA.

—(1994): "Más allá de la 'propiedad perfecta'. El proceso de privatización de los montes públicos españoles, 1859-1926", Noticiario de Historia Agraria, 8, pp. 99-142.

GUTIÉRREZ BRINGAS, Miguel Ángel (2000): La productividad de los factores en la agricultura española (1752-1935), Madrid, Banco de España.

HERRERO, María Ángeles (1993): Evolución de la propiedad agraria y de la renta de la tierra en el País Vasco durante el siglo XIX y principios del XX, Tesis Doctoral, Universidad de País Vasco.

KAROUZOU, Evi (1993): “Las reformas agrarias en Grecia, siglos XIX y XX”, Noticiario de Historia Agraria, 6, pp. 59-85.

KÖNING, Nieck (1994): The failure of agrarian capitalism. Agrarian politics in the United Kingdom, Germany, the Netherlands and the USA, 1846-1919, Londres y Nueva York, Routledge.

LANA BERASAIN, José Miguel (1997): Cambio agrario y relaciones de propiedad en el sur de Navarra, 1800-1936, Tesis Doctoral, Universidad de Zaragoza.

-(2002): "Jornales, salarios, ingresos. Aproximación a la evolución de los niveles de vida desde la Navarra rural, 1801-1936", MARTÍNEZ CARRIÓN, José Miguel (ed.), El nivel de vida en al España rural, siglos XVIII-XX, Alicante, Publicaciones de la Universidad de Alicante, pp.183-233.

LINDERT, Peter (2003): “Voice and Growth: was Churchill Right?" The Journal of Economic History, Vol. 63, 3, pp. 215-241.

LUPO, Salvatore (1990): Il giardini degli aranci. Il mondi degli agrumi nella storia del Mezzogiorno, Venecia, Marsilio.

LLOPIS, Enrique (2001): “El legado económico del Antiguo Régimen desde la óptica regional", GERMÁN, L., LLOPIS, E., MALUQUER DE MOTES, J., y ZAPATA, S., (eds.), Historia Económica regional de España, siglos XIX y XX, Barcelona, Crítica, pp. 507-524.

-(2002): “La crisis del Antiguo Régimen y la revolución liberal, 1790-1840”, COMIN, F., HERNÁNDEZ, M., y LLOPIS, E. (eds.), Historia económica de España. Siglos XXX, Barcelona, Crítica, pp. 165-202.

MARTÍNEZ CARRIÓN, José Miguel (1987): Desarrollo agrario y crecimiento económico en la región de Murcia, 1875-1935, tesis doctoral, Universidad de Murcia.

-(1999): "Agricultores e industriales en la industria del pimentón, 1840-1936", Revista de Historia Económica, XVII, 1, pp. 149-186.

-(2002a): Historia económica de la región de Murcia, siglos XIX y XX, Murcia, Editora Regional, pp. 405-460. 
MARTÍNEZ CARRIÓN, José Miguel, y PÉREZ CASTEJÓN, Juan José (2002): “Creciendo con desigualdad. Niveles de vida biológicos en la España rural mediterránea desde 1840", en MARTÍNEZ CARRIÓN, José Miguel (ed.), El nivel de vida en la España rural, siglos XVIII-XX, Alicante, Universidad de Alicante, pp. 405461.

MARTÍNEZ MARTIN, Manuel (1995): Revolución liberal y cambio agrario en la alta Andaluciá, Granada, Estudios Históricos, Chrónica Nova.

MARTÍNEZ SOTO, Ángel P. (1994): Crédito y ahorro popular. El crédito agrícola institucional en la región de Murcia, tesis doctoral, Murcia, Universidad de Murcia.

-(1998): “Las vías de financiación de la agricultura murciana entre 1870-1936: el problema del crédito agrícola", Agricultura y Sociedad, 84, pp. 49-106.

-(2000): “Cooperativismo y crédito agrario en la región de Murcia, 1890-1936", Historia Agraria, 20, pp. 123-168.

-(2001): “La tela de araña. Mercados informales de financiación agraria, usura y crédito hipotecario en la región de Murcia (1850-1939)", Áreas. Revista de Ciencias Sociales, 21, monográfico La financiación de los sistemas agrarios desde una perspectiva histórica, pp. 185-220.

MARTÍNEZ SOTO, Ángel P., y CUEVAS CASAÑA, Joaquín (coords.) (2001): La financiación de los sistemas agrarios en España desde una perspectiva histórica, Áreas. Revista de Ciencias Sociales, 21, monográfico La financiación de los sistemas agrarios desde una perspectiva histórica.

MILLÁN, Jesús (1999): El poder de la tierra, Alicante, Instituto Juan Gil Albert.

MORENO LÁZARO, Javier (2002): “¿Fomentó el capitalismo agrario la desigualdad? Salarios y niveles de vida en Castilla la Vieja, 1751-1861", en MARTÍNEZ CARRIÓN, José Miguel (ed.), El nivel de vida en la España rural, siglos XVIII-XIX, Alicante, Universidad de Alicante, pp. 75-113.

MORILLA CRITZ, José, OLMSTEAD, Alan L., y RHODE, PAUL W. (1999): “Horn of Plenty: The globalization of Mediterranean Horticultura and the Economic Development of Southern Europe, 1800-1930", The Journal of Economic History, 59, 2, pp. 316-350.

NADAL, Jordi (1987): “La industria fabril en España en 1900. Una aproximación", en NADAL, J., CARRERAS, A., y SUDRIÁ, C., (eds.), La economía española en el siglo XX. Una perspectiva histórica, Barcelona, Ariel, pp. 108-125.

NÚÑEZ, Clara Eugenia (1992): La fuente de la riqueza. Educación y desarrollo económico en la España contemporánea, Madrid, Alianza.

O'ROURKE, Kevin, y WILLIAMSON, Jeffrey (1997). "Around the European periphery 1870-1913. globalization, schooling and growth", European Review of Economic History, 1, pp. 153-190.

PARIAS, María (1989): El mercado de la tierra sevillana en el siglo XIX, Sevilla, Publicaciones de la Diputación Provincial. 
PECH, Remy (1975): Entreprise viticole et capitalisme en Languedoc-Rousillon du phylloxéra au crise de mévente, Toulouse, Publicaciones Universidad Tolouse-le-Mirail.

PÉREZ PICAZO, María Teresa (1987a): “Crédito y usura en la región murciana en el siglo XIX", Áreas, 8, pp. 9-21.

-(1987b): "Crédito hipotecario y cambio institucional en la región de Murcia (18361862)", Hacienda Pública Española, 108-109, pp. 361-377.

-(1990a): El mayorazgo en la historia económica de la región murciana. Expansión, crisis y abolición (S. XVII-XIX), Madrid, MAPA.

—(1990b): "Salarios y niveles de vida en la agricultura murciana durante el siglo XIX", Nivells de vida à Espanya, ss. XIX i XX, XV Simposi d'Anàlisi Económica, Universitat Autónoma de Barcelona, 18-19 diciembre.

—(1990c): "Pautas de industrialización de la región murciana. Del textil al agroalimentario", NADAL, Jordi y CARRERAS, Albert (eds.), Pautas regionales de la industrialización española. Barcelona, Ariel, pp. 315-341.

-(1991): "Riqueza territorial y cambio agrícola en la Murcia del siglo XIX. Aproximación al estudio de una contabilidad privada (circa 1800-1902)", Agricultura y Sociedad, 61, pp. 39-95.

-(1994): Grupos sociales, estructura productiva y explotación agraria en el Sureste español en los siglos XIX y XX. Informe final del Proyecto de Investigación PB91-0947, 29/4/94. Investigador principal.

-(1995): "Pequeña explotación y consolidación del capitalismo en las agriculturas mediterráneas (1850-1930)", en MORILLA, José (dir.), California y el Mediterráneo. Estudio de dos agriculturas competitivas, Madrid, MAPA, pp. 335-375.

-(1998): “Las estructuras agrarias”, en MORALES, Antonio (dir.), Bases políticas, económicas y sociales de un régimen en transformación (1759-1834), tomo XXX de la Historia de España de Menéndez Pidal, Madrid, Espasa Calpe, pp. 427-575.

-(2000): “Essor de la production et gains de la productivité agricole dans une région meditérranéenne au XIXe siècle. Le cas de Murcie", Histoire \& Mesure, 41, pp. 217232.

-(2004): “Economía campesina y mercado. El caso de las huertas del Segura en los siglos XIX y XX", en VICEDO, Enric (ed.), Fires, mercats i món rural, Lleida, Institut d'Estudis Illerdencs, pp. 15-42.

PÉREZ PICAZO, María Teresa, MARTÍNEZ CARRIÓN, José Miguel, y PÉREZ DE PERCEVAL, Miguel Ángel (1998): “Ceux qui peinent et ceux qui prennent. Conjoncture et modes de faire-valoir dans les systèmes agraires du Sud-Est espagnol (1830-1960)", Histoire et Societés Rurales, 10, pp. 47-81.

PÉREZ PICAZO, María Teresa, y MARTÍNEZ CARRIÓN, José Miguel (2001): “Murcia, crecimiento en un medio físico difícil", en GERMÁN, L., LLOPIS, E., MALUQUER DE MOTES, J., y ZAPATA, S., (eds.), Historia económica regional de España, siglos XIX y XX, Barcelona, Crítica, pp. 413-440. 
PÉREZ PICAZO, María Teresa, y PÉREZ DE PERCEVAL, Miguel Ángel (2004): “El mercado de la tierra en Murcia, 1836-1862", Historia Agraria, 32, pp. 59-88.

PETMEZAS, Sócrates (1997): "El comercio de la pasa de Corinto y su influencia sobre la economía griega en el siglo XIX", en MORILLA, José et al. (eds.), Impactos exteriores sobre el mundo rural mediterráneo, Madrid, MAPA, pp. 523-563.

POSTEL-VINAY, Gilles (1998): La terre et l'argent. L'agriculture et le crédit en France du XVIIIe au début du XX siècle, París, Albin Michel.

PUJOL, Joseph (2001): "La historiografía del atraso o el atraso de la historiografía”, en PUJOL, J., GONZÁLEZ DE MOLINA, M., FERNÁNDEZ PRIETO, L., GALLEGO, D., y GARRABOU, R., (eds.), El pozo de todos los males, Barcelona, Crítica, pp. 1342.

ROBLEDO, Ricardo (1984): La renta de la tierra en Castilla la Vieja y León, 1836-1913, Madrid, Banco de España.

-(2001): "Las bases del capitalismo agrario", en ROBLEDO, Ricardo (ed.), Historia de Salamanca. IV. Siglo XIX, Salamanca, Centro de Estudios Salmantinos, pp. 311-338. SABIO ALCUTÉN, Alberto (1992): “Las compraventas de tierra, una faceta de la integración mercantil forzosa del pequeño campesinado. Cariñena, 1886-1934", Noticiario de Historia Agraria, 4, pp. 315-334.

-(1996): Los mercados informales de crédito y tierra en una comunidad aragonesa (18501930), Madrid, Banco de España.

—(1998): "El capitalisme agrari a través de la renda en una agricultura orgànica. Les estratègies d'un ministre a finals del segle XIX a l'Aragó", Recerques, 37, pp. 57-80. SAGUER, Enric (1998a): “Estímulos y obstáculos al avance de la propiedad campesina (el Baix Empordá, 1860-1940)", Revista de Historia Económica, XVI, 3, pp. 677-706.

—(1998b): “La consolidación de la propiedad campesina en Cataluña: un análisis comparativo", Historia Agraria, 16, pp. 209-233.

SÁNCHEZ PICÓN, Andrés (2001): “Algunas cuestiones en torno al crédito agrario en Andalucía (1800-1936), Áreas, 21, pp.165-185.

SÁNCHEZ SALAZAR, Felipa (1988): Extensión de cultivos en España en el siglo XVIII, Madrid, Siglo XXI.

SIMPSON, James (1995): Spanish Agriculture. The Long Siesta, 1765-1965, Cambridge, Cambridge University Press.

-(2002): “El pozo de todos los males y el debate sobre el atraso agrario", Historia Agraria, 28, pp. 217-228.

VILAR RAMÍREZ, Juan, BEL ADELL, Carmen, y GÓMEZ FAYRÉN, Josefa (1999): Las migraciones murcianas contemporáneas, Murcia, Universidad de Murcia.

ZAPATA, Santiago (2001): "Apéndice estadístico", en GERMÁN, L., LLOPIS, E., MALUQUER DE MOTES, J., y ZAPATA, S., (eds.), Historia Económica regional de España, siglos XIX y XX, Barcelona, Crítica, pp. 561-597. 